Research Article

\title{
Coordination Mechanism of Supply Chain considering the Bullwhip Effect under Digital Technologies
}

\author{
Wenxue Ran, ${ }^{1}$ Yan Wang, ${ }^{2}$ Lifan Yang, ${ }^{1,3}$ and Sen Liu $\mathbb{D}^{1}$ \\ ${ }^{1}$ School of Logistics, Yunnan University of Finance and Economics, Kunming 650221, China \\ ${ }^{2}$ School of Business, Honghe University, Mengzi 661199, China \\ ${ }^{3}$ Faculty of Management and Economics, Kunming University of Science and Technology, Kunming 650504, China
}

Correspondence should be addressed to Sen Liu; liusencool@163.com

Received 12 March 2020; Revised 22 July 2020; Accepted 6 August 2020; Published 9 September 2020

Academic Editor: Massimiliano Ferrara

Copyright ( 92020 Wenxue Ran et al. This is an open access article distributed under the Creative Commons Attribution License, which permits unrestricted use, distribution, and reproduction in any medium, provided the original work is properly cited.

The bullwhip effect (BWE) and stochastic demand coexist in supply chain operation management, which leads to a lower performance. In recent years, with the development of blockchain, cloud computing, big data, and other digital technologies (DTs), many enterprises hope to use them to weaken the BWE and improve profits. This paper focuses on improving the application level of DTs in the supply chain through coordination for enhancing the performance. We consider a supply chain with one-supplier-one-retailer and coordinate it with the cost-sharing contract and revenue-cost-sharing contract (the improved contract). We find out that the retailer and supplier did not always have the willingness to use DTs to alleviate the BWE. Even if they have the intention to use DTs, their ideal application level is not the same. After coordination, both the application level of DTs and the performance of the supply chain are improved, and we find that the improved contract has a better coordination effect. Finally, we validate our model by numerical simulation.

\section{Introduction}

Nowadays, with the development of digital technologies (DTs), i.e., blockchain, cloud computing, and big data, new starting points arise for the scientific study of the supply chain coordination (SCC) [1-4]. In the field of practice, many famous companies, such as Apple, IBM, and WalMart, have also begun to participate in the application of DTs in company operation management, actively [5-8].

The bullwhip effect (BWE), which was initially found by Forrester in 1958 through a case study in supply chain management, can be effectively alleviated after the application of DTs [1]. Blockchain can alleviate the problems caused by information asymmetry in the supply chain $[3,9,10]$. Big data plays a crucial role in demand forecasting and reducing the BWE $[2,11,12]$. By supporting real-time information sharing within supply chains, cloud computing can reduce information inconsistency and time delays to minimize the BWE [13-16].
On the other hand, more business members in the supply chain make decentralized decisions [17]. Decentralized decision-making in a supply chain leads to two significant effects, the "double marginal effect" and the BWE [18]. The BWE widely exists in the supply chain, and it is one of the most concerned areas in the research of supply chain management [19-25].

Furthermore, market demand is becoming more and more stochastic due to the intensification of market competition and the uncertainty of consumer preferences [18]. How to manage stochastic demand effectively has become a core challenge for supply chain researchers and decisionmakers for the reason that stochastic demand will increase the difficulty of SCC and bring risks to sellers [26]. To avoid risks, supply chain members tend to increase further or reduce inventory (the BWE), which aggravates the supplydemand mismatch [27]. Therefore, this paper fully considers the stochastic demand as an essential factor in the analysis of the market demand faced by retailers. 
As mentioned above, the BWE exists widely in the supply chain, and market demand is becoming more and more random. Therefore, we should not ignore the existence of the BWE and the situation of stochastic demand when considering the distribution and coordination of interests of all stakeholders in the supply chain. Meanwhile, in the research of SCC involving the BWE, we must consider the application of DTs. Based on this, we propose an SCC model considering both the BWE and stochastic demand under DTs and the equilibrium solution solved by game theory.

This paper aims to incorporate the application level of DTs into the design of a coordination mechanism of supply chain management and establish a revenue-cost-sharing contract. Therefore, this study attempts to explain the following questions:

(1) How do the supplier and retailer make decisions about product quantity?

(2) To maximize the profits of the whole supply chain, which level of DT application should be adopted?

(3) Which type of coordination mechanism should be adopted?

Our work contributes to the literature in the following ways:

(1) The starting point of the existing research studies is the amplification effect of DTs on market demand by market segmentation, target market selection, and market positioning $[28,29]$. This consideration leads to the increase of ordering quantity and production quantity after the application of DTs. This study mainly considers the weakening effect of DTs on BWE, which leads to the decrease of ordering quantity and production quantity after the application of DTs.

(2) In addition, the existing research studies mainly use revenue sharing contract in coordination contract [30]. This paper combines revenue sharing contract and cost-sharing contract to form a cost-revenuesharing joint contract, which has a wider scope of application.

The remainder of the paper is structured as follows. In Section 2, we review the related literature. Section 3 illustrates the model description and notations. Section 4 discusses stakeholders' game considering the BWE and stochastic demand in the environment of DTs with decentralized and centralized decisions, respectively. Section 5 designs the coordination contract considering the BWE and stochastic demand under DTs. Section 6 shows numerical examples and an analysis of the raised models. The conclusions are presented in Section 7.

\section{Literature Review}

This paper attempts to investigate the cost-sharing and revenue-cost-sharing joint contract that are used to analyze the SCC problem with the BWE and stochastic demand in the environment of DTs. Thus, the literature review includes three main research streams: the DTs and the SCC, SCC considering the BWE, the SCC contracts in the environment of DTs. Table 1 compares the current research with the most similar works in this area.

\subsection{DTs and the Supply Chain Coordination}

2.1.1. Application of DTs in the Supply Chain. Nowadays, DTs are widely used in supply chain management. Artificial intelligence can be used to describe demand uncertainty in the supply chain [31, 32]. Some scholars explored the investment decision-making problems of big data information and its effects on the coordination of supply chain in the big data environment $[28,29,33-35]$. Blockchain can solve the problem of information sharing in the supply chain [30]. Internet of Things can be applied to improve the performance of the supply chain of perishable food [16]. Following the above tendency growth, the ranking of DTs in supply chain will become increasingly crucial. This transform will cause the change of supply chain management; i.e., DTs should be involved in the supply chain management. Therefore, we take it as a key parameter to investigate SCC.

2.1.2. SCC in the Environment of DTs. Many scholars have done research about SCC in the context of DTs. Bottani and Montanari [4] introduced RFID and EPC networks into the supply chain to reduce the BWE and improve the economic benefits of the whole fast consumer goods supply chain. RFID is used to reduce the total cost of inventory, improve inventory turnover, and reduce the BWE in the supply chain [36-38]. However, they generally do not consider the BWE on supply chain performance in the DT environment. On the contrary, this paper considers the weakening effect of DTs on BWE and establishes a decision-making model.

\subsection{Supply Chain Coordination considering the Bullwhip} Effect and/or Stochastic Demand. Although there are few studies on BWE in the context of DTs, some scholars have paid attention to BWE in the study of general supply chain coordination. These studies give us enlightenment.

The BWE refers to the distortion phenomenon when the order information is transmitted upstream; i.e., the fluctuation of the order variance is more significant when the order information goes upstream of the supply chain [39-41]. The BWE leads to massive inefficiencies, high risk, and cost, e.g., excessive inventories, poor customer service, and lost revenue $[39,42]$. Costantino et al. [43] thought that information could not be shared is the root cause of the BWE; besides, inaccurate predictions and high-security stocks are factors that produce the BWE. A substantive amount of the literature shows that information sharing among supply chain participants can considerably alleviate the BWE $[44,45]$ because the most crucial reason for the BWE is the existence of uncertain demand and information asymmetry [46]. Tai et al. [25] paid much attention to SCC with the BWE and stochastic demand, but they did not consider the environment of DTs. Some scholars have 
TABLE 1: Summary of the related literature.

\begin{tabular}{|c|c|c|c|c|c|c|c|c|c|c|}
\hline \multirow[b]{2}{*}{ Literature } & \multicolumn{6}{|c|}{ Type of contract } & \multirow[b]{2}{*}{ Involves } & \multirow[b]{2}{*}{$\begin{array}{l}\text { Involves } \\
\text { the BWE }\end{array}$} & \multirow[b]{2}{*}{$\begin{array}{l}\text { Involves } \\
\text { stochastic } \\
\text { demand }\end{array}$} & \multirow[b]{2}{*}{ Involves DTs } \\
\hline & $\begin{array}{l}\text { Revenue- } \\
\text { sharing }\end{array}$ & $\begin{array}{c}\text { Rewarding- } \\
\text { punishing }\end{array}$ & $\begin{array}{l}\text { Joint } \\
\text { contracts }\end{array}$ & $\begin{array}{l}\text { Two- } \\
\text { part } \\
\text { tariff }\end{array}$ & $\begin{array}{l}\text { Wholesale } \\
\text { price }\end{array}$ & $\begin{array}{l}\text { Cost- } \\
\text { sharing }\end{array}$ & & & & \\
\hline $\mathrm{Xu}$ et al. [28] & $\sqrt{ }$ & & & & & & & & & Big data \\
\hline Liu [29] & $\sqrt{ }$ & & & & & $\sqrt{ }$ & & & & Big data \\
\hline Liu et al. [30] & $\sqrt{ }$ & & & & & & & $\sqrt{ }$ & $\sqrt{ }$ & Blockchain \\
\hline $\begin{array}{l}\text { Liu and Yi } \\
\text { [33] }\end{array}$ & $\sqrt{ }$ & & & & & & & & & Big data \\
\hline $\begin{array}{l}\text { Liu and Yi } \\
\text { [34] }\end{array}$ & $\sqrt{ }$ & & & & & & & & & Big data \\
\hline $\mathrm{Xu}$ et al. [75] & $\sqrt{ }$ & & $\sqrt{ }$ & & & & & & $\sqrt{ }$ & \\
\hline $\begin{array}{l}\text { Guo et al. } \\
\text { [31] }\end{array}$ & $\sqrt{ }$ & & & & & & & & $\sqrt{ }$ & $\begin{array}{c}\text { Artificial } \\
\text { intelligence }\end{array}$ \\
\hline $\begin{array}{l}\text { Zheng et al. } \\
\text { [76] }\end{array}$ & & & & $\sqrt{ }$ & & & & & & \\
\hline $\begin{array}{l}\text { Yenipazarli } \\
\text { [79] }\end{array}$ & $\sqrt{ }$ & & & & & $\sqrt{ }$ & & & & \\
\hline $\begin{array}{l}\mathrm{Hu} \text { and Feng } \\
\text { [27] }\end{array}$ & $\sqrt{ }$ & & & & & & & & $\sqrt{ }$ & \\
\hline $\begin{array}{l}\text { Liu and Yi } \\
\text { [35] }\end{array}$ & $\sqrt{ }$ & & & & & & & & & Big data \\
\hline Li et al. [70] & $\sqrt{ }$ & & & & & & & & $\sqrt{ }$ & Blockchain \\
\hline $\begin{array}{l}\text { Zhang et al. } \\
\text { [71] }\end{array}$ & $\sqrt{ }$ & & & & & $\sqrt{ }$ & & & & \\
\hline $\begin{array}{l}\text { Pezeshki } \\
\text { et al. [74] }\end{array}$ & & $\sqrt{ }$ & & & & & & & & \\
\hline $\mathrm{Ha}[73]$ & $\sqrt{ }$ & & & & $\sqrt{ }$ & & & & $\sqrt{ }$ & \\
\hline $\begin{array}{l}\text { Song et al. } \\
\text { [80] }\end{array}$ & $\sqrt{ }$ & & & & & $\sqrt{ }$ & & & & \\
\hline This paper & $\sqrt{ }$ & & & & & $\sqrt{ }$ & $\sqrt{ }$ & $\sqrt{ }$ & $\sqrt{ }$ & $\sqrt{ }$ \\
\hline
\end{tabular}

This paper combines a revenue-sharing contract with a cost-sharing contract to a revenue-cost-sharing joint contract.

expanded Tai's research. They believe sharing POS data, using the intelligence approach, artificial neural network, and information integration across the supply chain can also effectively reduce the BWE in the supply chain under a stochastic demand environment [47, 48]. Kochan et al. [49] also proposed that cloud computing can improve supply chain performance by reducing the BWE.

The proportional order-up-to policy can alleviate the BWE and demand uncertainty [50]. Keshari et al. [51] proved that optimal multiple order-up-to policy-based inventory replenishment scheme could alleviate the BWE. Tai et al. [25] measured the BWE of price-sensitive demand of a two-stage supply chain with a supplier and a retailer. Similarly, other scholars have studied the existence, causes, and solutions of the BWE from different perspectives [43, 52-55]. Recently, there are many works on the BWE in specific industries. For example, the reverse supply chain optimization of electronic products and positive recovery activities can effectively alleviate the BWE [56]. Through the study of the European automotive parts supply chain, it can be concluded that the BWE of fast-moving products is higher than that of slowmoving products [57]. Some approaches, such as vendor managed inventory [58] and smoothing inventory decision rules [59], can also reduce the effect of the BWE.

$\mathrm{Hu}$ and Feng [27] use a revenue-sharing contract with service demand to study the optimization and coordination of the supply chain under the supply and demand uncertainty. Many scholars proposed an operations management model with a discount at wholesale price to induce the retailer to adjust its order quantity and retail price based on joint decision-making in the supply chain, which faces with stochastic price-sensitive demand [60]. Cai et al. [61] introduced an option contract to clarify that the option contract can coordinate the supply chain under both deterministic demand and stochastic demand, and supply chain participants can achieve Pareto improvement. Li et al. [62] established a model to study the effects of demand uncertainty and stochastic output fluctuation on the production scheduling and purchasing strategies of manufacturers and retailers, respectively. Besides, many other works also studied the supply chain model with uncertainty $[27,63-65]$. On the basis of the aforementioned works, this paper considers the BWE and stochastic demand under DTs, simultaneously, which is more practical.

2.3. Supply Chain Coordination Contracts. Finally, we review the literature on SCC contracts. To address the supply chain performance problem with bullwhip effect and stochastic demand in the context of DTs, we investigate the literature stream related to our topic, summarized in Table 1. We summarized the following four types of SCC contracts: (i) 
Revenue-sharing contract: it has been widely studied and implemented in supply chain [27]. It is found that the supply chain coordination can be achieved by introducing revenue sharing contract under the retailer's profit constraint based on the two-level supply chain of a retailer and a supplier [66]. By studying the efficiency of reverse supply chains in the PC industry, Govindan and Popiuc [67] pointed out that revenue sharing contracts can improve the performance of twolevel and three-level reverse supply chains. Palsule-Desai [68] argued that revenue-dependent revenue sharing contract is better than independent revenue contract in supply chain coordination, pointed out that the former can provide positive earnings for supply chain participants, and expounded the impact of multistage contract settings on supply chain coordination revenue sharing contract. Li et al. $[69,70]$ researched supply chain coordination under the combined effects of block chain technology and random demand and designed a brand-new supply chain coordination model through revenue sharing contract. (ii) Costsharing contract: in general, cost-sharing contract is used in conjunction with revenue-sharing contracts to coordinate supply chain [30]. Zhang et al. [71] analyzed the situation of a one-manufacturer-one-retailer and designed revenuesharing and cost-sharing mechanisms to coordinate the supply chain. They pointed out that contracts can fully coordinate supply chains in most cases only when the revenue share ratio is roughly $1 / 2$ and $3 / 4$. The combination of cost-sharing contract and revenue-sharing contract can better coordinate the supply chain than the separate revenue-sharing contract. Without the former, revenue-sharing contract cannot achieve supply chain coordination perfectly. (iii) Wholesale price contract: generally, wholesale price contracts are used in conjunction with revenue-sharing contracts to overcome the disadvantage that wholesale price contracts can only benefit retailers but not manufacturers $[72,73]$. Hu et al. found that to coordinate the supply chain with supply uncertainty, the supplier will be provided a higher revenue sharing ratio or a larger wholesale price than that without supply uncertainty. (iv) Others: in addition, the types of supply chain coordination involve other contracts: rewarding-punishing [74], subsidy [75], wholesale price or price discount [75], two-part tariff [76], quantity discount, and so on [77]. Pezeshki et al. [74] studied the coordination of a decentralized supply chain with one supplier and several retailers and proposed a trust-based incentive-penalty coordination mechanism. In today's complex economic operations, the traditional revenue sharing contract can no longer coordinate the supply chain under the background of random yield and stochastic demand but can coordinate the supply chain by combining with the improved revenue sharing contract, i.e., earnings subsidy mechanism [78]. Hu and Feng [27] and $\mathrm{Hu}$ et al. [66] prove that the effect of supplier's expected profit on wholesale price under wholesale price contract is pseudo-concave and deduce the supplier's optimal wholesale price under the restriction of retailer's profit margin.

In today's complex economic operations, the traditional revenue-sharing contract can no longer coordinate the supply chain under the background of random yield and stochastic demand. Fortunately, the improved revenuesharing contract can do it, i.e., earnings subsidy mechanism [78], wholesale price [27, 66], cost- and revenue-sharing contract $[79,80]$, cooperative investment contract [71], and revenue-dependent revenue-sharing contract [68]. Therefore, this paper combines a revenue-sharing contract with a cost-sharing contract to a revenue-cost-sharing contract to optimize the supply chain performance.

To the best of our knowledge, SCC has attracted many scholars' attention. Some scholars have noticed the BWE in their research, but they paid little attention to the SCC in the environment of DTs. Revenue-sharing contract and costsharing contract and other forms of contract are also widely used in the existing studies. In SCC, few scholars considered the impact of DTs on BWE, which is not consistent with the wide application of DTs in practice. At the same time, a revenue-cost-sharing joint contract is adopted rarely. In contrast to these studies, we consider a SCC problem in the context of DTs. This paper focuses the SCC models that integrate the BWE and stochastic demand under DTs and uses a revenue-cost-sharing joint contract to study the SCC problem. More importantly, we capture the reality that the BWE increases waste in supply chain management. As a result, we have obtained different results from those of previous scholars. Such scenario is more in line with the actual situation of economic operation, and it is of great significance in both theory and practice.

\section{Model}

3.1. Model Descriptions. We consider a two-echelon supply chain that consists of a supplier and a retailer. The supplier is responsible for producing products and selling them to the retailer at wholesale price $P_{s}$, whereas the retailer is responsible for selling products to customers at a retail price $P_{r}$. Due to the BWE, the retailer makes decisions on the order quantity $D$ based on the enlarged market demand $y$, not the actual market demand $x$. Similarly, the supplier's production quantity $Q$ is larger than the retailer's order quantity $D$ due to the BWE, as shown in Figure 1.

Retailer and supplier are willing to adopt DTs to reduce the BWE to improve supply chain performance. However, supplier and retailer make decisions on the application level of DTs in the supply chain based on their interests. When the ideal application level of DTs is different, we believe that the level determined by the party whose expectation is lower or leads to the unwillingness of the party with low application level of DTs to cooperate. We assume that both the supplier and the retailer share the cost of applying DTs.

The proposed models are developed and based on the following assumptions:

Assumption 1. All stakeholders in the supply chain are of self-interest and risk-neutral. Neither the supplier nor the retailer has the ability to dominate the supply chain; that is to say, their cooperation premise is negotiation, not determined by the leading party. 


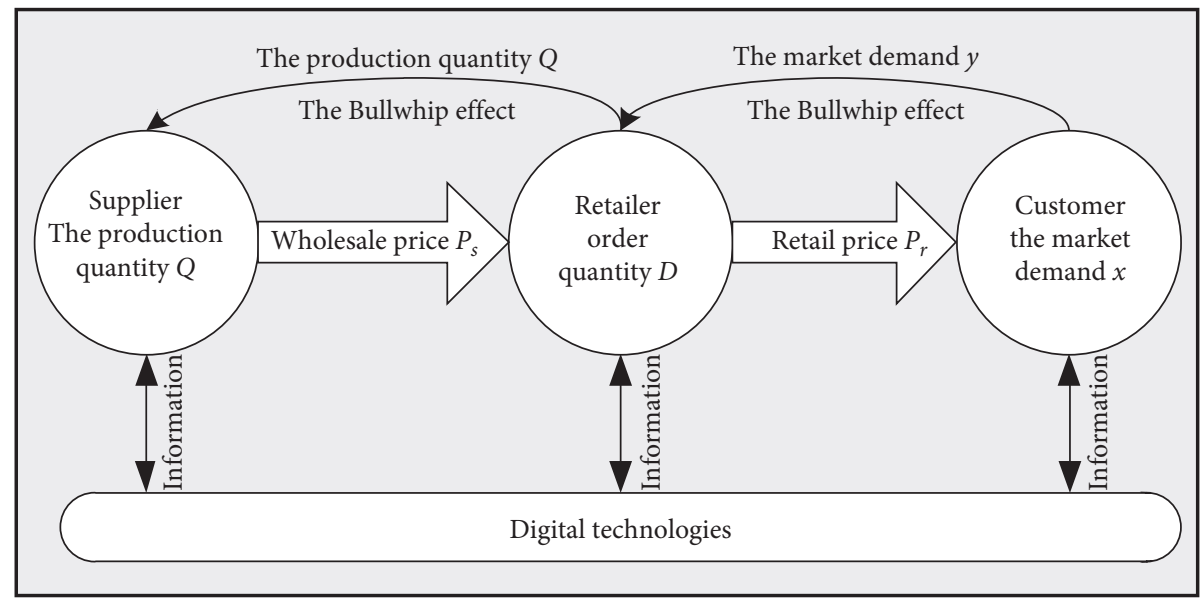

FIgURE 1: The relations among participants in the supply chain under DTs.

Assumption 2. The product demand $x$ is a nonnegative and continuous random variable, having probability density function $f(x)$ and cumulative distribution function $F(x)$ which is continuous and differentiable, $F(0)=0$ and $x \in[0,+\infty)$.

Assumption 3. Because of the BWE, the retailer's order quantity and the supplier's production quantity are not based on the actual market demand $x$, but on the enlarged market demand $y$. As in the study [30], we also assume that under the double influence of the BWE and DTs, the retailer's hypothetical market demand $y$ and the supplier's determined production quantity $Q$ are shown in

$$
\left\{\begin{array}{l}
y=x+\left(1-\theta^{2}\right) \alpha, \\
Q=D+\left(1-\theta^{2}\right) \alpha,
\end{array}\right.
$$

where $\theta$ is the application degree of DTs in the supply chain and $\alpha$ is the influence degree of the BWE.

What should be noted is that retailers are faced with random market demand. While the market demand faced by suppliers is the retailer's order quantity, we can assume that it is a fixed market.

Assumption 4. We assume that the application of DTs in the supply chain can effectively alleviate the BWE, and as shown in Formula (1), when the application degree of DTs reaches 1 , the BWE can be completely overcome [30].

Assumption 5. The salvage value $v$ of unsold products is less than the unit cost $c_{s}$ of the manufacturer and the cost $c_{r}$ of the retailer, and there is no shortage in the model. It shows that both retailers and suppliers will try to sell their products and avoid inventory.

Assumption 6. The introduction of DTs will bring additional costs to all parties in the supply chain. According to Banker et al. [81], we assume the cost of DTs $c_{B}$ as follows:

$$
c_{B}=\lambda \theta^{2},
$$

Assumption 7. The premise of cooperation among supply chain members is that their profits should be no less than their respective reservation profits, while the sum of their reservation profits is not higher than the maximum profitability of the supply chain.

Assumption 8. $\theta_{\mathrm{sc}}^{*}=\min \left\{\theta_{s}^{*}, \theta_{r}^{*}\right\}$. It shows that for the party who expects a lower level of DT application, if the level is too high, it will bring a high cost, so that he will not agree to adopt a high application level. However, for the party who expects a higher degree, the lower degree also brings extra benefits rather than not using DTs, so he is willing to make a compromise.

3.2. Notations and Definitions. Table 2 summarizes notations and definitions used throughout the paper.

\section{Benchmark Model considering the BWE under DTs}

4.1. Model under Decentralized Decision-Making. On the premise of the fact that applying DTs can alleviate the BWE in supply chain, supply chain members make decisions to maximize their profiles. The decision-making order of both parties is as follows: First, suppliers and retailers determine $\theta$ according to their expected profit conditions and then determine $\theta$ in the supply chain through negotiation. Second, the retailer determines the order quantity $D$ according to the enlarged market demand $y$. Third, the supplier determines the production quantity $Q$ according to the order quantity of the retailer.

By backward induction, the expected profits of retailer's "enlargement" are as follows (Note: the expected profits is the retailer's imaginary rather than the real expected profits because the retailer enlarges the real demand and then decides the optimal order quantity, whereas the actual demand of the market is not so significant which is precisely the harm what the BWE brings to the supply chain.):

$$
E\left(\pi_{r}^{d}\right)=\left(p_{r}-p_{s}-c_{r}\right) D^{d}-\left(p_{r}-v\right) \times \int_{t}^{D^{d}} F(y-t) \mathrm{d} y-\lambda\left(\theta_{r}^{d}\right)^{2},
$$

where $\lambda$ is a certain constant. 
TABLE 2: Model parameters and meaning.

\begin{tabular}{lc}
\hline Parameters & Definition \\
\hline$x$ & Market demand \\
$y$ & Amplified demand of retailer under the BWE \\
$D$ & Retailer's order quantity \\
$Q$ & Production quantity of supplier \\
$c_{s}$ & The unit production cost of supplier \\
$c_{r}$ & The unit cost of the retailer \\
$c_{B}$ & Additional costs of introducing DTs in the supply chain \\
$p_{r}$ & Retailer price \\
$\alpha$ & The impact parameter of the BWE on supply chain \\
$v$ & Unit salvage value of unsold goods \\
$E$ & Expectation \\
$\pi$ & Profits \\
\hline$\pi^{0}$ & Reservation profits \\
Decision variables & Definition \\
$\theta$ & The application level of DTs in the supply chain \\
$h$ & Revenue-sharing ratio \\
$g$ & Cost-sharing ratio \\
\hline$W$
\end{tabular}

We use subscripts $r, s$, and sc to represent the retailer, supplier, and supply chain, respectively. Similarly, superscripts $c, d$, cs, and rcs are used to represent the scenario of the centralized decision-making, decentralized decision-making, cost-sharing contract, and revenue-cost-sharing contract, respectively.

where $t=\left(1-\left(\theta_{r}^{d}\right)^{2}\right) \alpha$.

The optimal order quantity of the retailer and the application level of DTs are as follows:

$$
\begin{array}{ll} 
\begin{cases}\theta_{r}^{d *}=\sqrt{1-\frac{F^{-1}\left(\left(p_{r}-p_{s}-c_{r} / p_{r}-v\right)+\left(\lambda / \alpha\left(p_{r}-v\right)\right)\right)-F^{-1}\left(p_{r}-p_{s}-c_{r} / p_{r}-v\right)}{\alpha},} & \text { A, } \\
\theta_{r}^{d *}=0, & \text { others, }\end{cases} \\
\begin{cases}D^{d *}=F^{-1}\left(\frac{p_{r}-p_{s}-c_{r}}{p_{r}-v}+\frac{\lambda}{\alpha\left(p_{r}-v\right)}\right), & A, \\
D^{d *}=F^{-1}\left(\frac{p_{r}-p_{s}-c_{r}}{p_{r}-v}\right)+a, & \text { others, }\end{cases}
\end{array}
$$

where condition $\mathrm{A}$ is $F^{-1}\left(\left(p_{r}-p_{s}-c_{r} / p_{r}-v\right)+(\lambda /\right.$ $\left.\left.\alpha\left(p_{r}-v\right)\right)\right) \leq \alpha+F^{-1}\left(p_{r}-p_{s}-c_{r} / p_{r}-v\right)$.

See Appendix A for the specific solution.

Combining (1) and (5), we can obtain the supplier's production quantity as follows:

$$
\begin{aligned}
Q^{d *} & =D^{d *}+\left(1-\theta^{2}\right) \alpha \\
& =F^{-1}\left(\frac{p_{r}-p_{s}-c_{r}}{p_{r}-v}\right)+2\left(1-\theta^{2}\right) \alpha .
\end{aligned}
$$

The real expected profits of the supplier are as follows:

$$
E\left(\pi_{s}^{d}\right)=p_{s} D^{d *}-c_{s} Q^{d *}+v\left(Q^{d *}-D^{d *}\right)-\lambda\left(\theta_{s}^{d}\right)^{2} .
$$

The expected $\theta_{s}^{d *}$ obtained by the supplier according to his own profit maximization condition is shown as followsfd8:

$$
\left\{\begin{array}{l}
\theta_{s}^{d *}=1, \quad-p_{s}+2 c_{s}-v>\frac{\lambda}{\alpha}, \\
\theta_{s}^{d *}=0, \quad-p_{s}+2 c_{s}-v<\frac{\lambda}{\alpha} .
\end{array}\right.
$$

See Appendix B for the specific solution.

In (8), the first inequality indicates that the supplier wishes the application level of DTs in the supply chain to be 1 and the second inequality indicates that the supplier wishes the level to be 0 .

Combining (4) and (8) can obtain the application level of DTs in the supply chain as follows: 


$$
\begin{cases}\theta_{\mathrm{sc}}^{d *}=\sqrt{\frac{F^{-1}\left(\left(p_{r}-p_{s}-c_{r} / p_{r}-v\right)+\left(\lambda / \alpha\left(p_{r}-v\right)\right)\right)-F^{-1}\left(p_{r}-p_{s}-c_{r} / p_{r}-v\right)}{\alpha},} & B, \\ \theta_{\mathrm{sc}}^{d *}=0, & \text { others, }\end{cases}
$$

where condition $\mathrm{B}$ is $A \cup\left(-p_{s}+2 c_{s}-v>(\lambda / \alpha)\right)$, meaning that as long as any of these conditions are satisfied.
Proposition 1. The optimal order quantity of the retailer, the production quantity of the supplier, and the profits of both participants are as follows, respectively:

$$
\begin{aligned}
& \begin{cases}D^{d *}=F^{-1}\left(\frac{p_{r}-p_{s}-c_{r}}{p_{r}-v}+\frac{\lambda}{\alpha\left(p_{r}-v\right)}\right), & B, \\
D^{d *}=F^{-1}\left(\frac{p_{r}-p_{s}-c_{r}}{p_{r}-v}\right)+\alpha, & \text { others, }\end{cases} \\
& \begin{cases}Q^{d *}=2 F^{-1}\left(\frac{p_{r}-p_{s}-c_{r}}{p_{r}-v}+\frac{\lambda}{\alpha\left(p_{r}-v\right)}\right)-F^{-1}\left(\frac{p_{r}-p_{s}-c_{r}}{p_{r}-v}\right), & B \\
Q^{d *}=F^{-1}\left(\frac{p_{r}-p_{s}-c_{r}}{p_{r}-v}\right)+2 \alpha, & \text { others, }\end{cases} \\
& \left\{\begin{array}{l}
E\left(\pi_{s}^{d *}\right)=p_{s} D^{d *}-c_{s} Q^{d *}+v\left(Q^{d *}-D^{d *}\right)-\lambda\left(\theta_{\mathrm{sc}}^{d *}\right)^{2} \\
E\left(\pi_{s}^{d *}\right)=\left(p_{r}-p_{s}-c_{r}\right) D^{d *}-\left(p_{r}-v\right) \int_{0}^{D^{d *}} F(x) \mathrm{d} x-\lambda\left(\theta_{\mathrm{sc}}^{d *}\right)^{2}
\end{array}\right.
\end{aligned}
$$

From Proposition 1, we find that the following:

(1) The retailer and supplier's expectation of the application level of DTs is different in the supply chain with the BWE and stochastic demand. Their application of the same level of DTs is the result of commercial compromise. When condition B is satisfied, the supplier does not reach the optimal decision, and the retailer cannot reach the optimal decision in other cases.

(2) The application of DTs will effectively reduce the order quantity of the retailer and the production quantity of the supplier is closer to the real market demand, which can effectively reduce the risk and cost while increasing profits of the supply chain.

(3) Whether the supplier or retailer adopts DTs is affected by the BWE, market uncertainty, and additional costs brought by the application of DTs. When the growth of profits brought by the application of DTs is lower than that of the additional cost, neither the supplier nor retailer is driven by DTs. On the contrary, they wish to apply DTs as high as possible to reduce the impact of the BWE.

Because the probability density function $f(x)$ cannot be derived, further conclusions are given in Section 6.
4.2. Model under Centralized Decision-Making. Under centralized decision-making, due to information sharing, the BWE affects less on the supply chain $[19,82,83]$. Referring to the above literature, we assume that the BWE in the supply chain is reduced to $\alpha_{1}$. In this case, the market demand of the supply chain is that of retailer, i.e., $y=x+\left(1-\theta^{2}\right) \alpha_{1}$. As mentioned above, the magnified demand $y$ obeys the probability density function $f\left(y-\left(1-\theta^{2}\right) \alpha_{1}\right)$, and its cumulative distribution function $F\left(y-\left(1-\theta^{2}\right) \alpha_{1}\right)$ is continuous and differentiable, $y \in\left[\left(1-\theta^{2}\right) \alpha_{1},+\infty\right]$.

In the case of centralized decision-making, the retailer and supplier make centralized decisions to determine $\theta$ according to the profit maximization of the supply chain. Then, the retailer decides the order quantity according to the market demand $y$ and the supplier determines the production quantity $Q$ according to the order quantity $D$ of the retailer.

By backward induction, after the market demand is enlarged, the profits of the supply chain are as follows:

$$
\begin{aligned}
E\left(\pi_{\mathrm{sc}}^{c}\right)= & \left(p_{r}-c_{s}-c_{r}\right) D^{c}-\left(p_{r}-v\right) \int_{t^{\prime}}^{D^{c}} F\left(y-t^{\prime}\right) d y \\
& +v\left(Q^{c}-D^{c}\right)-2 \lambda\left(\theta_{\mathrm{sc}}^{c}\right)^{2},
\end{aligned}
$$

where 


$$
\left\{\begin{array}{l}
t^{\prime}=\left(1-\left(\theta_{\mathrm{sc}}^{c}\right)^{2}\right) \alpha_{1} \\
Q^{c}=D^{c}+t^{\prime}
\end{array}\right.
$$

The first derivative and second derivative are as follows, respectively:

$$
\left\{\begin{array}{l}
\frac{\mathrm{d} E\left(\pi_{\mathrm{sc}}^{c}\right)}{\mathrm{d} D^{c}}=\left(p_{r}-c_{s}-c_{r}\right)-\left(p_{r}-v\right) F\left(D^{c}-t \prime\right), \\
\frac{\mathrm{d}^{2} E\left(\pi_{\mathrm{sc}}^{c}\right)}{\mathrm{d} D^{c 2}}=-\left(p_{r}-v\right) f\left(D^{c}-t^{\prime}\right) .
\end{array}\right.
$$

There exists an optimal solution of the function, which can be obtained according to the first-order condition:

$$
D^{c *}=F^{-1}\left(\frac{p_{r}-c_{s}-c_{r}}{p_{r}-v}\right)+t^{\prime} .
$$

Therefore, the real expected profits of the supply chain are as follows:

$$
\begin{aligned}
E\left(\pi_{\mathrm{sc}}^{c}\right)= & \left(p_{r}-c_{s}-c_{r}\right) D^{c *}-\left(p_{r}-v\right) \\
& \times \int_{0}^{D^{c *}} F(x) \mathrm{d} x+v\left(Q^{c *}-D^{c *}\right)-2 \lambda\left(\theta_{\mathrm{sc}}^{c}\right)^{2} .
\end{aligned}
$$

Proposition 2. The optimal order quantity of the retailer and the application level of DTs are as follows:

$$
\left\{\begin{array}{l}
\theta_{\mathrm{sc}}^{c *}=\sqrt{1-\frac{F^{-1}\left(\left(\alpha_{1}\left(p_{r}-c_{s}-c_{r}+v\right)+2 \lambda\right) / \alpha_{1}\left(p_{r}-v\right)\right)-F^{-1}\left(p_{r}-c_{s}-c_{r} / p_{r}-v\right)}{\alpha_{1}}}, \\
D^{c *}=F^{-1}\left(\frac{\alpha_{1}\left(p_{r}-c_{s}-c_{r}+v\right)+2 \lambda}{\alpha_{1}\left(p_{r}-v\right)}\right), \\
Q^{c *}=2 F^{-1}\left(\frac{\alpha_{1}\left(p_{r}-c_{s}-c_{r}+v\right)+2 \lambda}{\alpha_{1}\left(p_{r}-v\right)}\right)-F^{-1}\left(\frac{p_{r}-c_{s}-c_{r}}{p_{r}-v}\right),
\end{array}\right.
$$

where

$$
F^{-1}\left(\frac{\alpha_{1}\left(p_{r}-c_{s}-c_{r}+v\right)+2 \lambda}{\alpha_{1}\left(p_{r}-v\right)}\right)<\alpha_{1}+F^{-1}\left(\frac{p_{r}-c_{s}-c_{r}}{p_{r}-v}\right) .
$$

Consequently, the profits of the supply chain are

$$
\begin{aligned}
E\left(\pi_{\mathrm{sc}}^{c}\right)^{*}= & \left(p_{r}-c_{s}-c_{r}\right) D^{c *}-\left(p_{r}-v\right) \\
& \times \int_{0}^{D^{c *}} F(x) \mathrm{d} x+v\left(Q^{c *}-D^{c *}\right)-2 \lambda\left(\theta_{\mathrm{sc}}^{c}\right)^{2} .
\end{aligned}
$$

\section{Coordination of Supply Chain}

According to the preceding paragraphs, because the supplier and the retailer have different $\theta^{*}$ under decentralized decision-making, the cooperation reached is the result of a commercial compromise, which is very common in practice. As a result, the party who expects the high $\theta$ cannot achieve Pareto optimization. In order to encourage those who expect low $\theta$ to improve it, we adopt the following strategies.

Strategy 1 is to adopt the cost-sharing contract. That is, in order to encourage the other party to improve $\theta$, the party who expects the high $\theta$ should share part of the cost of DT application to the other party.
Because after the coordination of the cost-sharing contract, the party with lower $\theta$ obtains net income, while the party with higher $\theta$ pays the cost at the same time. When the cost is high but the benefit is low, the party who originally expected the high $\theta$ is not willing to enter into such a contract. Therefore, we adopt strategy 2.

Strategy 2 is to adopt cost-revenue-sharing contract. On the basis of cost-sharing contract, the party with low $\theta$ will share part of the profits after the promotion of DTs to the other party to encourage him to accept the contract.

This section will answer the following questions: Can cost-sharing contract and revenue-cost-sharing contract achieve Pareto improvement compared with coordination before? What is the respective scope of application of these two contracts? What are the advantages of a revenue-costsharing contract over the cost-sharing contract?

5.1. Cost-Sharing Contract. We follow the same cost-sharing contract model as Liu [29], Song et al. [80], Yenipazarli [79], and Zhang et al. [71]. The "cost-sharing" mentioned in this paper refers to that the party with the higher mathematical expectation of DT application-level encourages the other party to improve the application level by undertaking a portion of the cost for the other party.

When $-p_{s}+2 c_{s}-v>(\lambda / \alpha)$, the supplier wants a higher level of application of DTs (means $\theta_{s}^{*}=1$ ); hence, the costsharing refers to that the supplier undertakes a portion of the 
cost of DT application for the retailer to improve the application level in the supply chain. When $-p_{s}+2 c_{s}-v<(\lambda / \alpha)$, cost-sharing refers to the retailer undertaking a portion of the cost for the supplier to improve the application level of DTs in the supply chain:

(1) When $-p_{s}+2 c_{s}-v>(\lambda / \alpha)$ is established, the profits of the retailer after coordination of supply chain costsharing are as follows:

$$
\begin{aligned}
E\left(\pi_{r}^{\mathrm{cs}}\right)= & \left(p_{r}-p_{s}-c_{r}\right) D^{\mathrm{cs}}-\left(p_{r}-v\right) \\
& \int_{\left(1-\left(\theta_{r}^{\mathrm{cs}}\right)^{2}\right) \alpha}^{D^{\mathrm{cs}}} F\left(y-\left(1-\left(\theta_{r}^{\mathrm{cs}}\right)^{2}\right) \alpha\right) \mathrm{d} y-g \lambda\left(\theta_{r}^{\mathrm{cs}}\right)^{2} .
\end{aligned}
$$

where $0 \leq g \leq 1$; it means that the supplier undertakes a portion of the cost for the retailer.

Concurrently, we should also pay attention to the fact that supplier's profits function has changed after SCC, so it needs to be satisfied $-p_{s}+2 c_{s}-v \geq((2-g) \lambda / \alpha)$, because only in this case, the level of application of DTs that the supplier wishes is 1 .

According to the first-order condition, the optimal order quantity for the retailer is

$$
D^{c s *}=F^{-1}\left(\frac{p_{r}-p_{s}-c_{r}}{p_{r}-v}\right)+\left(1-\left(\theta_{r}^{c s}\right)^{2}\right) \alpha .
$$

Retailer determines the application level of DTs based on the real mathematical expectation of profits

$$
E\left(\pi_{r}^{c s}\right)=\left(p_{r}-p_{s}-c_{r}\right) D^{c s *}-\left(p_{r}-v\right) \int_{0}^{D^{c s *}} F(x) \mathrm{d} x-g \lambda\left(\theta_{r}^{c s}\right)^{2} .
$$

According to the first-order condition, we can obtain Proposition 3.

When $-p_{s}+2 c_{s}-v>(\lambda / \alpha)$ is established, the optimal $\theta$ and $D$ of retailer are as follows:

$$
\left\{\begin{array}{l}
\theta_{r}^{\mathrm{cs} *}=\sqrt{1-\frac{F^{-1}\left(\left(p_{r}-p_{s}-c_{r} / p_{r}-v\right)+\left(g \lambda / \alpha\left(p_{r}-v\right)\right)\right)-F^{-1}\left(p_{r}-p_{s}-c_{r} / p_{r}-v\right)}{\alpha}}, \\
D^{\mathrm{cs} *}=F^{-1}\left(\frac{p_{r}-p_{s}-c_{r}}{p_{r}-v}+\frac{g \lambda}{\alpha\left(p_{r}-v\right)}\right),
\end{array}\right.
$$

where

$$
\left\{\begin{array}{l}
F^{-1}\left(\frac{p_{r}-p_{s}-c_{r}}{p_{r}-v}+\frac{g \lambda}{\alpha\left(p_{r}-v\right)}\right)<\alpha+F^{-1}\left(\frac{p_{r}-p_{s}-c_{r}}{p_{r}-v}\right) \\
\frac{p_{r}-p_{s}-c_{r}}{p_{r}-v}+\frac{g \lambda}{\alpha\left(p_{r}-v\right)}<1 .
\end{array}\right.
$$

$$
E\left(\pi_{s}^{\mathrm{cs}}\right)=p_{s} D^{\mathrm{cs} *}-c_{s} Q^{\mathrm{cs}}+v\left(Q^{\mathrm{cs}}-D^{\mathrm{cs} *}\right)-(2-g) \lambda \theta_{r}^{\mathrm{cs}} *^{2} .
$$

where $Q^{\text {cs }}=D^{\text {cs* }}+\left(1-\theta_{s}^{c s} *^{2}\right) \alpha$.

The analytical solution cannot be obtained in this case, but the optimal ratio of cost-sharing $g^{*}$ can be solved by the MATLAB numerical method. By substituting it into equations (21), (22), and (24), the order/production quantities and profits of each player after SCC can be obtained. See Section 6 for numerical solutions.

Proposition 3. When $-p_{s}+2 c_{s}-v>(\lambda / \alpha)$ is established, the optimal $\theta, D, Q$, and $\pi$ are as follows:

$$
\left\{\begin{array}{l}
\theta_{r}^{c s *}=\sqrt{1-\frac{F^{-1}\left(\left(p_{r}-p_{s}-c_{r} / p_{r}-v\right)+\left(g^{*} \lambda / \alpha\left(p_{r}-v\right)\right)\right)-F^{-1}\left(p_{r}-p_{s}-c_{r} / p_{r}-v\right)}{\alpha}}, \\
D^{\mathrm{cs} *}=F^{-1}\left(\frac{p_{r}-p_{s}-c_{r}}{p_{r}-v}+\frac{g^{*} \lambda}{\alpha\left(p_{r}-v\right)}\right), \\
Q^{\mathrm{cs} *}=2 F^{-1}\left(\frac{p_{r}-p_{s}-c_{r}}{p_{r}-v}+\frac{g^{*} \lambda}{\alpha\left(p_{r}-v\right)}\right)-F^{-1}\left(\frac{p_{r}-p_{s}-c_{r}}{p_{r}-v}\right)
\end{array}\right.
$$


where

$$
\begin{aligned}
& \left\{\begin{array}{l}
F^{-1}\left(\frac{p_{r}-p_{s}-c_{r}}{p_{r}-v}+\frac{g \lambda}{\alpha\left(p_{r}-v\right)}\right)<\alpha+F^{-1}\left(\frac{p_{r}-p_{s}-c_{r}}{p_{r}-v}\right) \\
\frac{p_{r}-p_{s}-c_{r}}{p_{r}-v}+\frac{g \lambda}{\alpha\left(p_{r}-v\right)}<1,
\end{array}\right. \\
& \left\{\begin{array}{l}
E\left(\pi_{r}^{\mathrm{cs} *}\right)=\left(p_{r}-p_{s}-c_{r}\right) D^{\mathrm{cs} *}-\left(p_{r}-v\right) \int_{0}^{D^{c s *}} F(x) d x-g^{*} \lambda\left(\theta_{r}^{\mathrm{cs}}\right) *^{2}, \\
E\left(\pi_{s}^{\mathrm{cs} *}\right)=p_{s} D^{\mathrm{cs} *}-c_{s} Q^{\mathrm{cs} *}+v\left(Q^{\mathrm{cs} *}-D^{\mathrm{cs} *}\right)-\left(2-g^{*}\right) \lambda\left(\theta_{r}^{c s}\right) *^{2} .
\end{array}\right.
\end{aligned}
$$

In this case, the profits of the retailer must be greater than those before coordination. As long as the profits after SCC are greater than or equal to the profits before coordination, the supplier is willing to participate in SCC. Thus, we can obtain Proposition 4.

Proposition 4. In order to reach the cost-sharing contract, the cost-sharing proportion conditions are as follows:

$$
E\left(\pi_{s}^{\mathrm{cs} *}\right) \geq E\left(\pi_{s}^{d *}\right),-p_{s}+2 c_{s}-v>\frac{\left(2-g^{*}\right) \lambda}{\alpha} .
$$

Equation (27) denotes that under the condition $-p_{s}+2 c_{s}-v>\left(\left(2-g^{*}\right) \lambda / \alpha\right)$, we can obtain $E\left(\pi_{s}^{\mathrm{cs} *}\right) \geq E\left(\pi_{s}^{d *}\right)$.

When (27) is satisfied, SCC can be achieved. See Section 6 for numerical analysis.

(2) When $-p_{s}+2 c_{s}-v<(\lambda / \alpha)$ is established, the costsharing contract is slightly different because in this case, the supplier wishes the application level of DTs to be zero, so the retailer only needs to compensate the supplier to $-p_{s}+2 c_{s}-v \geq((2-g) \lambda / \alpha)$ (the retailer undertakes a portion of the cost for the supplier, and thus, $1 \leq g \leq 2$ ). The retailer only needs to compensate the supplier to $-p_{s}+2 c_{s}-v=((2-g) \lambda / \alpha)$; in this case, the retailer undertakes the lowest DT cost after coordination, whereas the supplier's profits are independent of the application level of DTs.

In this case, the application level of DTs of the supply chain and the order quantity of the retailer are as follows:

$$
\left\{\begin{array}{l}
\theta_{\mathrm{sc}}^{\mathrm{cs} *}=\sqrt{1-\frac{F^{-1}\left(\left(p_{r}-p_{s}-c_{r} / p_{r}-v\right)+\left(g \lambda / \alpha\left(p_{r}-v\right)\right)\right)-F^{-1}\left(p_{r}-p_{s}-c_{r} / p_{r}-v\right)}{\alpha}}, \\
D_{r}^{\mathrm{cs} *}=F^{-1}\left(\frac{p_{r}-p_{s}-c_{r}}{p_{r}-v}+\frac{g \lambda}{\alpha\left(p_{r}-v\right)}\right)
\end{array}\right.
$$

where

$$
\left\{\begin{array}{l}
F^{-1}\left(\frac{p_{r}-p_{s}-c_{r}}{p_{r}-v}+\frac{g \lambda}{\alpha\left(p_{r}-v\right)}\right)<\alpha+F^{-1}\left(\frac{p_{r}-p_{s}-c_{r}}{p_{r}-v}\right) \\
\frac{p_{r}-p_{s}-c_{r}}{p_{r}-v}+\frac{g \lambda}{\alpha\left(p_{r}-v\right)}<1 .
\end{array}\right.
$$

The retailer's cost-sharing ratio is

$$
g^{*}=2-\left(-p_{s}+2 c_{s}-v\right) \frac{\alpha}{\lambda} .
$$

Proposition 5. Substituting (30) into (21) and (28), we obtain the application level of DTs after SCC, as well as the order quantity of the retailer, the production quantity of the supplier, and the profits of both players:

$$
\left\{\begin{array}{l}
\theta_{\mathrm{sc}}^{\mathrm{cs} *}=\sqrt{1-\frac{F^{-1}\left(\left(p_{r}-p_{s}-c_{r} / p_{r}-v\right)+\left(g^{*} \lambda / \alpha\left(p_{r}-v\right)\right)\right)-F^{-1}\left(p_{r}-p_{s}-c_{r} / p_{r}-v\right)}{\alpha},} \\
D^{c s *}=F^{-1}\left(\frac{p_{r}-p_{s}-c_{r}}{p_{r}-v}+\frac{g^{*} \lambda}{\alpha\left(p_{r}-v\right)}\right), \\
Q^{c s *}=2 F^{-1}\left(\frac{p_{r}-p_{s}-c_{r}}{p_{r}-v}+\frac{g^{*} \lambda}{\alpha\left(p_{r}-v\right)}\right)-F^{-1}\left(\frac{p_{r}-p_{s}-c_{r}}{p_{r}-v}\right),
\end{array}\right.
$$


where

$$
\begin{aligned}
& \left\{\begin{array}{l}
F^{-1}\left(\frac{p_{r}-p_{s}-c_{r}}{p_{r}-v}+\frac{g^{*} \lambda}{\alpha\left(p_{r}-v\right)}\right)<\alpha+F^{-1}\left(\frac{p_{r}-p_{s}-c_{r}}{p_{r}-v}\right), \\
\frac{p_{r}-p_{s}-c_{r}}{p_{r}-v}+\frac{g^{*} \lambda}{\alpha\left(p_{r}-v\right)}<1,
\end{array}\right. \\
& \left\{\begin{array}{l}
E\left(\pi_{r}^{\mathrm{cs} *}\right)=\left(p_{r}-p_{s}-c_{r}\right) D^{\mathrm{cs} *}-\left(p_{r}-v\right) \int_{0}^{D^{\mathrm{cs} *}} F(x) d x-g^{*} \lambda\left(\theta_{\mathrm{sc}}^{\mathrm{cs} *}\right)^{2}, \\
E\left(\pi_{s}^{\mathrm{cs} *}\right)=p_{s} D^{\mathrm{cs} *}-c_{s} Q^{\mathrm{cs} *}+v\left(Q^{\mathrm{cs} *}-D^{\mathrm{cs} *}\right)-\left(2-g^{*}\right) \lambda\left(\theta_{\mathrm{sc}}^{\mathrm{cs} *}\right)^{2} .
\end{array}\right.
\end{aligned}
$$

Similar to the above, the profits of the supplier must be no less than that before coordination. As long as the retailer's profits are greater than or equal to the profits before coordination, she is willing to participate in SCC, meaning

$$
E\left(\pi_{r}^{\mathrm{cs} *}\right) \geq E\left(\pi_{r}^{d *}\right),-p_{s}+2 c_{s}-v=\frac{\left(2-g^{*}\right) \lambda}{\alpha} .
$$

Equation (33) represents that when the condition $-p_{s}+$ $2 c_{s}-v=\left(\left(2-g^{*}\right) \lambda / \alpha\right)$ is satisfied, we obtain $E\left(\pi_{r}^{\mathrm{cs} *}\right) \geq E\left(\pi_{r}^{d *}\right)$.

When (33) is satisfied, SCC can be achieved. See Section 6 for numerical analysis.

From Propositions 4 and 5 , when $-p_{s}+2 c_{s}-v \geq((2-$ $\left.g^{*}\right) \lambda / \alpha$ ) is established, the supply chain coordinated by costsharing contract can improve the retailer's profits but not reduce the supplier's profits, simultaneously. When $-p_{s}+$ $2 c_{s}-v<\left(\left(2-g^{*}\right) \lambda / \alpha\right)$ is established, SCC improved the supplier's profits but did not reduce the retailer's profits. That is to say, Pareto improvement can be achieved by coordinating the supply chain through a cost-sharing contract.

5.2. Revenue-Cost-Sharing Contract. We combined the costsharing contract model according to Liu [29], Song et al. [80], Yenipazarli [79], and Zhang et al. [71] with the revenue-sharing contract model obtained by Xu et al. [28] and Li et al. [70] into revenue-cost-sharing contract.

Cost-sharing contract and revenue-sharing contract are widely used, but as far as we know, there is no revenue-costsharing contract in the real world, which is one of the innovation points of this paper.

Through the above research, we find that Pareto improvement can be achieved by the cost-sharing contract, and the profits of the supplier and retailer can improve to a certain extent. However, the margin of profits increase is limited, and the scope of application of the contract is narrow (see Section 6 for numerical analysis). Therefore, we further considered a revenue-sharing contract together with a cost-sharing contract. In this scenario, the decisionmaking order is as follows: first, the party who expects a higher $\theta$ promises to encourage the other party to improve $\theta$ by undertaking part of the cost of DT application (the same as the cost-sharing contract).

Then, because the party with low $\theta$ obtains net income, while the other party will pay extra cost, this will cause the latter to refuse the contract on some conditions. At this point, the former encourages the latter to reach a contract by promising to share proportion $h$ of the revenue to him.

The expected profits of the retailer are as follows:

$$
\begin{aligned}
E\left(\pi_{r}^{\mathrm{rcs}}\right)= & h\left(p_{r}-p_{s}-c_{r}\right) D^{\mathrm{rcs}}-h\left(p_{r}-v\right) \\
& \cdot \int_{\left(1-\left(\theta_{r}^{\mathrm{rcs}}\right)^{2}\right) \alpha}^{D^{\mathrm{rcs}}} F\left(y-\left(1-\left(\theta_{r}^{\mathrm{rcs}}\right)^{2}\right) \alpha\right) \mathrm{d} y-g \lambda\left(\theta_{r}^{\mathrm{rcs}}\right)^{2} .
\end{aligned}
$$

Similarly,

$$
\begin{cases}-p_{s}+2 c_{s}-v \geq \frac{(2-g) \lambda}{\alpha}, & 0 \leq g \leq 1, \\ \text { otherwise, } & 1 \leq g \leq 2 .\end{cases}
$$

According to the first-order condition, the optimal order quantity of the retailer is

$$
D^{\mathrm{rcs} *}=F^{-1}\left(\frac{p_{r}-p_{s}-c_{r}}{p_{r}-v}\right)+\left(1-\left(\theta_{r}^{\mathrm{rcs}}\right)^{2}\right) \alpha .
$$

As mentioned above, the retailer determines the application level of DTs based on real expected profits:

$$
\begin{aligned}
E\left(\pi_{r}^{\mathrm{rcs}}\right)= & h\left(p_{r}-p_{s}-c_{r}\right) D^{\mathrm{rcs} *}-h\left(p_{r}-v\right) \\
& \cdot \int_{0}^{D^{\mathrm{rcs} *}} F(x) \mathrm{d} x-g \lambda\left(\theta_{r}^{\mathrm{rcs}}\right)^{2} .
\end{aligned}
$$

According to the first-order condition, we can obtain 


$$
\left\{\begin{array}{l}
\theta_{r}^{\mathrm{rcs} *}=\sqrt{1-\frac{F^{-1}\left(\left(p_{r}-p_{s}-c_{r} / p_{r}-v\right)+\left(g \lambda / \alpha h\left(p_{r}-v\right)\right)\right)-F^{-1}\left(p_{r}-p_{s}-c_{r} / p_{r}-v\right)}{\alpha}} \\
D^{\mathrm{rcs} *}=F^{-1}\left(\frac{p_{r}-p_{s}-c_{r}}{p_{r}-v}+\frac{g \lambda}{\alpha h\left(p_{r}-v\right)}\right)
\end{array}\right.
$$

where

$$
\left\{\begin{array}{l}
F^{-1}\left(\frac{p_{r}-p_{s}-c_{r}}{p_{r}-v}+\frac{g \lambda}{\alpha h\left(p_{r}-v\right)}\right)<\alpha+F^{-1}\left(\frac{p_{r}-p_{s}-c_{r}}{p_{r}-v}\right) \\
\frac{p_{r}-p_{s}-c_{r}}{p_{r}-v}+\frac{g \lambda}{\alpha h\left(p_{r}-v\right)}<1 .
\end{array},\right.
$$

In this case, the supplier's profits are as follows:

$$
\begin{aligned}
E\left(\pi_{s}^{\mathrm{rcs}}\right)= & (1-h) E\left(R^{*}\right)+p_{s} D^{\mathrm{rcs} *} \\
& -c_{s} Q^{\mathrm{rcs}} v\left(Q^{\mathrm{rcs}}-D^{\mathrm{rcs} *}\right)-(2-g) \lambda\left(\theta_{s}^{r c s}\right)^{2},
\end{aligned}
$$

where

$$
\left\{\begin{array}{l}
Q^{\mathrm{rcs}}=D^{\mathrm{rcs} *}+\left(1-\theta_{s}^{\mathrm{rcs} 2}\right) \alpha, \\
E\left(R^{*}\right)=\left(p_{r}-p_{s}-c_{r}\right) D^{\mathrm{rcs} *}-\left(p_{r}-v\right) \int_{0}^{D^{\mathrm{rcs} *}} F(x) \mathrm{d} x .
\end{array}\right.
$$

According to the first-order condition, the level of application of DTs, the production, and order quantities are as follows:

$$
\left\{\begin{array}{l}
\theta_{s}^{\mathrm{rcs} *}=\sqrt{1-\frac{D^{\mathrm{rcs} *}-F^{-1}\left(p_{r}-p_{s}-c_{r} / p_{r}-v\right)}{\alpha}}, \\
Q^{\mathrm{rcs} *}=2 D^{\mathrm{rcs} *}-F^{-1}\left(\frac{p_{r}-p_{s}-c_{r}}{p_{r}-v}\right), \\
D^{\mathrm{rcs} *}=F^{-1}\left(\frac{\alpha\left(p_{s}-2 c_{s}+v\right)+(2-g) \lambda}{\alpha(1-h)\left(p_{r}-v\right)}+\frac{p_{r}-p_{s}-c_{r}}{p_{r}-v}\right),
\end{array}\right.
$$

where

$$
\left\{\begin{array}{l}
D^{\mathrm{rcs} *}<\alpha+F^{-1}\left(\frac{p_{r}-p_{s}-c_{r}}{p_{r}-v}\right) \\
\frac{\alpha\left(p_{s}-2 c_{s}+v\right)+(2-g) \lambda}{\alpha(1-h)\left(p_{r}-v\right)}+\frac{p_{r}-p_{s}-c_{r}}{p_{r}-v}<1 .
\end{array}\right.
$$

See Appendix D for the solution process.

After SCC, supply chain cooperation can be achieved as long as the corresponding application level of DTs and the order quantity of the retailer are equally between (42) and (38). That is,

$$
h^{*}=g \frac{\lambda}{\alpha\left(p_{s}-2 c_{s}+v\right)+2 \lambda} .
$$

Proposition 6. The application level of DTs in the supply chain, retailer's order quantity, supplier's production quantity, and their profits can be obtained, respectively, by substituting (44) into (38) and (42):

$$
\left\{\begin{array}{l}
\theta_{\mathrm{sc}}^{\mathrm{rcs} *}=\sqrt{1-\frac{D^{\mathrm{rcs} *}-F^{-1}\left(p_{r}-p_{s}-c_{r} / p_{r}-v\right)}{\alpha},} \\
Q^{\mathrm{rcs} *}=2 D^{r c s *}-F^{-1}\left(\frac{p_{r}-p_{s}-c_{r}}{p_{r}-v}\right), \\
D^{\mathrm{rcs} *}=F^{-1}\left(\frac{p_{r}-p_{s}-c_{r}}{p_{r}-v}+\frac{\alpha\left(p_{s}-2 c_{s}+v\right)+2 \lambda}{\alpha\left(p_{r}-v\right)}\right),
\end{array}\right.
$$

where

$$
\begin{aligned}
& \left\{\begin{array}{l}
D^{\mathrm{rcs} *}<\alpha+F^{-1}\left(\frac{p_{r}-p_{s}-c_{r}}{p_{r}-v}\right), \\
\frac{p_{r}-p_{s}-c_{r}}{p_{r}-v}+\frac{\alpha\left(p_{s}-2 c_{s}+v\right)+2 \lambda}{\alpha\left(p_{r}-v\right)}<1,
\end{array}\right. \\
& \left\{\begin{array}{l}
E\left(\pi_{r}^{\mathrm{rcs} *}\right)=h^{*} E\left(R_{r}^{*}\right)-g \lambda \theta_{r}^{\mathrm{rcs}} *^{2}, \\
E\left(\pi_{s}^{\mathrm{rcs} *}\right)=\left(1-h^{*}\right) E\left(R_{r}^{*}\right)+E\left(R_{s}^{*}\right)-(2-g) \lambda \theta_{r}^{\mathrm{rcs}} *^{2},
\end{array}\right.
\end{aligned}
$$

where

$$
\left\{\begin{array}{l}
E\left(R_{r}^{*}\right)=\left(p_{r}-p_{s}-c_{r}\right) D^{\mathrm{rcs} *}-\left(p_{r}-v\right) \int_{0}^{D^{\mathrm{rcs} *}} F(x) \mathrm{d} x \\
E\left(R_{s}^{*}\right)=p_{s} D^{\mathrm{rcs} *}-c_{s} Q^{\mathrm{rcs} *}+v\left(Q^{\mathrm{rcs} *}-D^{\mathrm{rcs} *}\right)
\end{array}\right.
$$

The profits of both the supplier and the retailer are higher than those before the coordination by revenue-costsharing contract so that both parties will participate in the coordination. Here, the retailer's reservation profits are those that the retailer can obtain before SCC, so as the supplier. That is, the improvement of Pareto must be achieved by the contract, i.e., 


$$
\left\{\begin{array}{l}
E\left(\pi_{r}^{\mathrm{rcs} *}\right) \geq \pi_{r}^{0}=E\left(\pi_{r}^{d *}\right), \\
E\left(\pi_{s}^{\mathrm{rcs} *}\right) \geq \pi_{s}^{0}=E\left(\pi_{s}^{d *}\right) .
\end{array}\right.
$$

Therefore, we can obtain the expression of the revenuesharing ratio $h^{*}$ as follows:

$$
\left\{\begin{array}{l}
h^{*} \geq \frac{E\left(\pi_{r}^{\mathrm{rcs} *}\right)+\left(p_{s}+c_{r}\right) D^{\mathrm{rcs} *}+g \lambda \theta_{r}^{\mathrm{rcs}} *^{2}}{E\left(R^{*}\right)}, \\
h \leq 1-\frac{E\left(\pi_{s}^{\mathrm{rcs} *}\right)-p_{s} D^{*}+c_{s} Q^{\mathrm{rcs} *}}{E\left(R^{*}\right)}-\frac{v\left(Q^{\mathrm{rcs} *}-D^{\mathrm{rcs} *}\right)-(2-g) \lambda \theta_{r}^{\mathrm{rcs}} *^{2}}{E\left(R^{*}\right)} .
\end{array}\right.
$$

The first inequality in (49) indicates the condition that the retailer's profits after SCC are not less than the reservation profits. When the expression is equal, it means that the supplier is dominant in the supply chain, and the retailer can only obtain reservation profits. The second inequality in (49) indicates the condition that the supplier's profits after SCC are not less than the reservation profits. When the expression is equal, it means that the retailer is dominant in the supply chain, and the supplier can only obtain reservation profits. When these two expressions cannot obtain equal signs at the same time, it means that neither of them has an absolute advantage. In this case, the proportion of revenue-cost-sharing is related to the bargaining power of both players.

\section{Numerical Examples and Analysis}

We provide some numerical examples to confirm the results derived in the previous sections and examine the performance of the proposed coordination mechanism by comparing the cost-sharing contract with the revenue-costsharing contract model. We use MATLAB to complete the numerical calculation and analysis in this section. We assume that the market demand follows a normal distribution. The problem we may face, like many authors [84-86] who used normal distributions have, is the generation of negative values, which can be avoided if the mean is large enough compared to the standard deviation. Specific parameters are shown in the following.

Market demand follows a normal distribution $\left(1000, \sigma^{2}\right)$. Here, different $\sigma$ indicate the level of uncertainty in market demand. Like other researchers, we make the following assumptions in numerical simulation: (1) In order to ensure that both the retailer and the supplier can obtain profits, the retail price should be higher than the sum of the wholesale price and the retailer's cost, whereas the wholesale price should be greater than the supplier's production cost. (2) The residual value of the unsold products at the end of the period is less than the cost, which is mainly to make the retailer and the supplier not blindly expand their order or production quantity; otherwise, it is inconsistent with the actual situation. (3) We assume that the impact of BWE on order/production quantity is demand amplification, but it will not make retailers and suppliers fundamentally misjudge market demand. Based on the above three assumptions, we suppose that the values of the

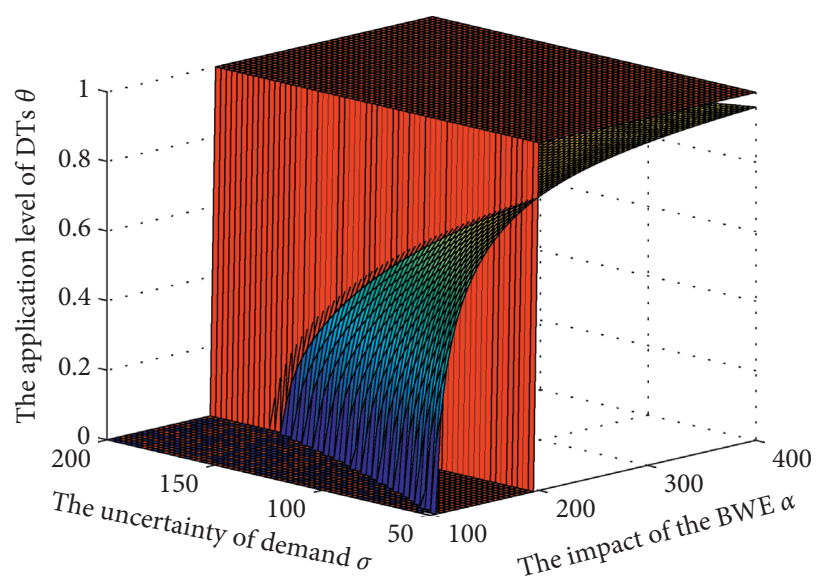

The supplier The retailer

FIgURE 2: The impact of the BWE and stochastic demand on the ideal application level of DTs of supply chain stakeholders.

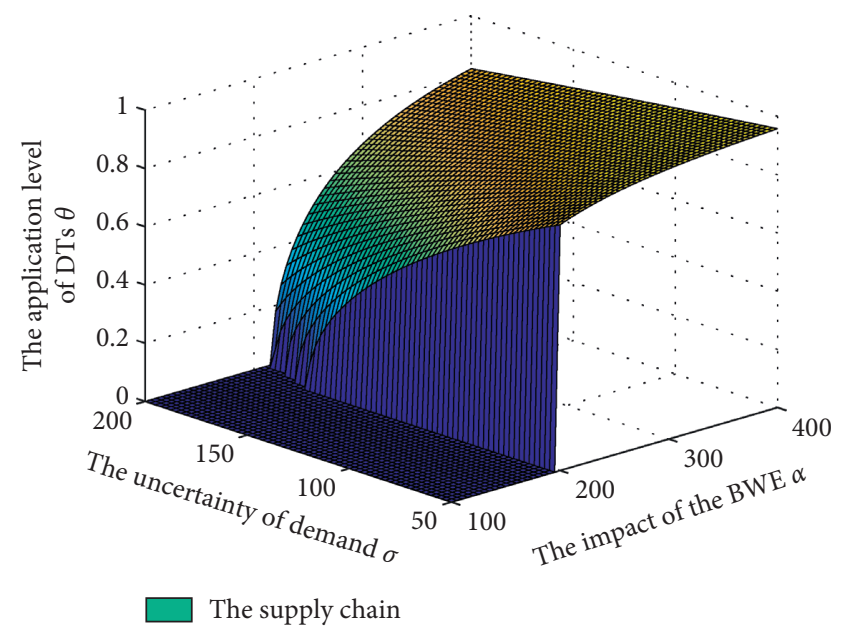

FIgURe 3: Actual DT application level of the supply chain under the coinfluence of the BWE and stochastic demand.

parameters are $p_{r}=17, p_{s}=13, c_{r}=2, c_{s}=10, \lambda=1200, v=$ 1 , and $\alpha \in[100,500]$; here, different $\alpha$ indicate the different levels of impact of the BWE.

6.1. Impact of the BWE and Market Uncertainty on the Application Level of DTs under Decentralized Decision-Making. Combining Figures 2-4, we find the following: (1) $\theta^{*}$ increases in $\alpha$ but decreases in $\sigma$. (2) Before point B, the retailer's expected $\theta$ is higher than that of the supplier, but after point $B$, the situation is opposite.

This is mainly because when the BWE is large in the supply chain, all channel members in the supply chain will suffer great losses due to the BWE. Both parties are willing to weaken the BWE by improving $\theta$. For the retailer, the greater the randomness of market demand, the less predictable the market will be. At this time, improving $\theta$ will make the order quantity closer to the expected value of market demand. However, due to the randomness of market demand, this kind of "more reasonable" order quantity does not 


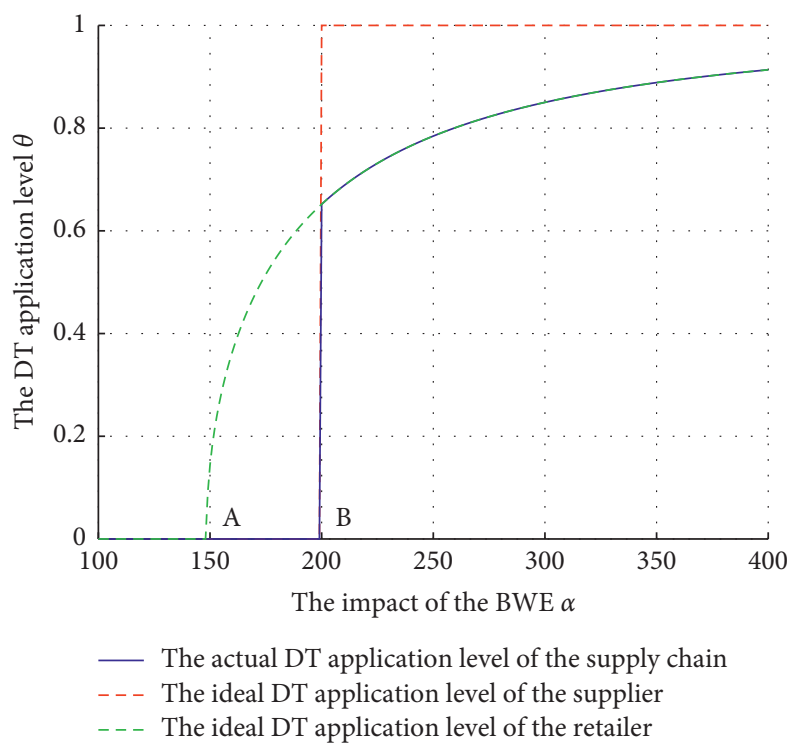

FIgURE 4: The BWE on the application level of DTs of supply chain stakeholders $(\sigma=100)$.

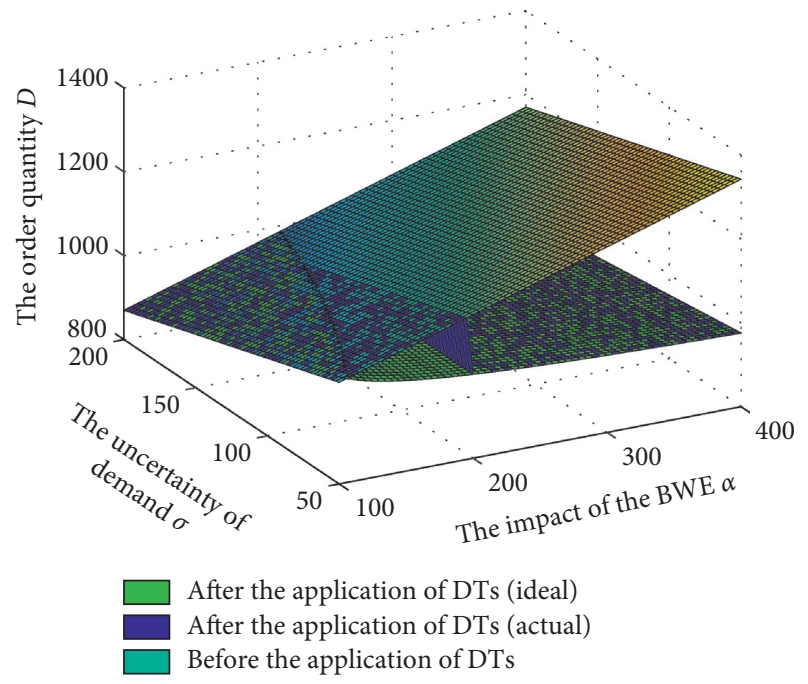

FIGURE 5: Impact of the BWE and market uncertainty on retailer's order quantity.

necessarily bring profit increase. On the contrary, the application of digital technology will bring a higher cost. So, $\theta^{*}$ decreases in $\sigma$.

Combining Figures 5-8, we can find that $q_{r}$ and $q_{s}$ increase in $\alpha$. However, when DTs are applied, the order quantity and production volume will be reduced.

This is mainly because in the supply chain, the BWE will make retailer and supplier misjudge the market situation. This increases the order quantity/production volume, and this will inevitably lead to losses due to the increase of inventory and other reasons. After the application of DTs, because of the weakening of BWE, the retailer and supplier can forecast the real market demand more accurately. So, they all reduce the order/production to a more reasonable level.

Combining Figures 9-12, we can find that both retailer and supplier's profits decrease in $\alpha$. In addition, after the

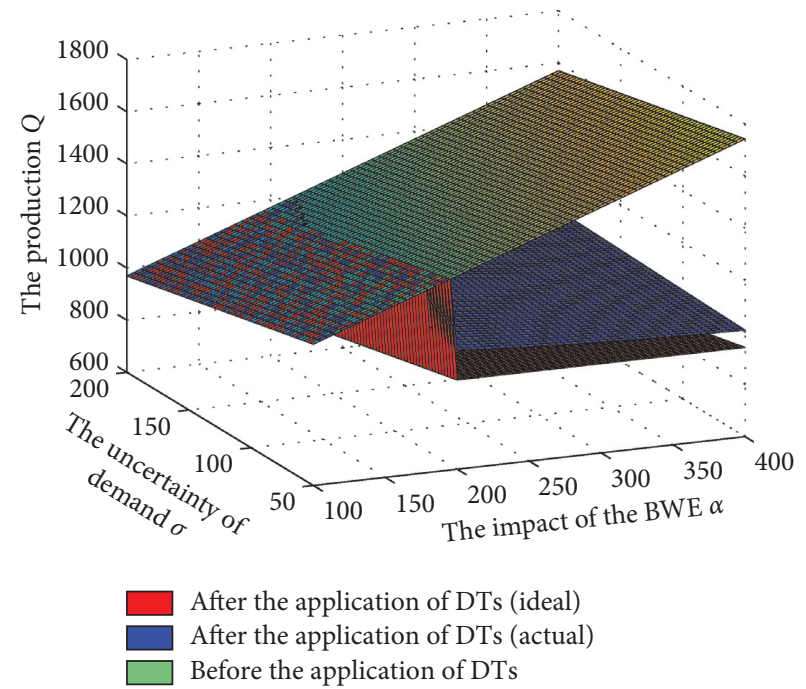

FIGURE 6: Impact of the BWE and market uncertainty on supplier's production.

application of DTs (after point B in Figures 11 and 12), the profits of both sides will be improved to a certain extent. Of course, we can also find that, before point B in Figures 11 and 12 , they did not apply DTs.

This is mainly because of the effect of the BWE, and the retailer and supplier will increase orders and production. This leads to greater losses. The application of DTs will make the order quantity and production volume more in line with the actual demand, to reduce the loss and improve the profit. Before point $\mathrm{B}$, the retailer and supplier did not adopt DTs because the benefits from adopting DTs were not enough to cover their costs.

6.2. Impact of the BWE and Market Uncertainty on the Application of DTs under Centralized Decision-Making. Combining Figures 4 and 13, we can find that after centralized decision-making, the application level of DTs in the 


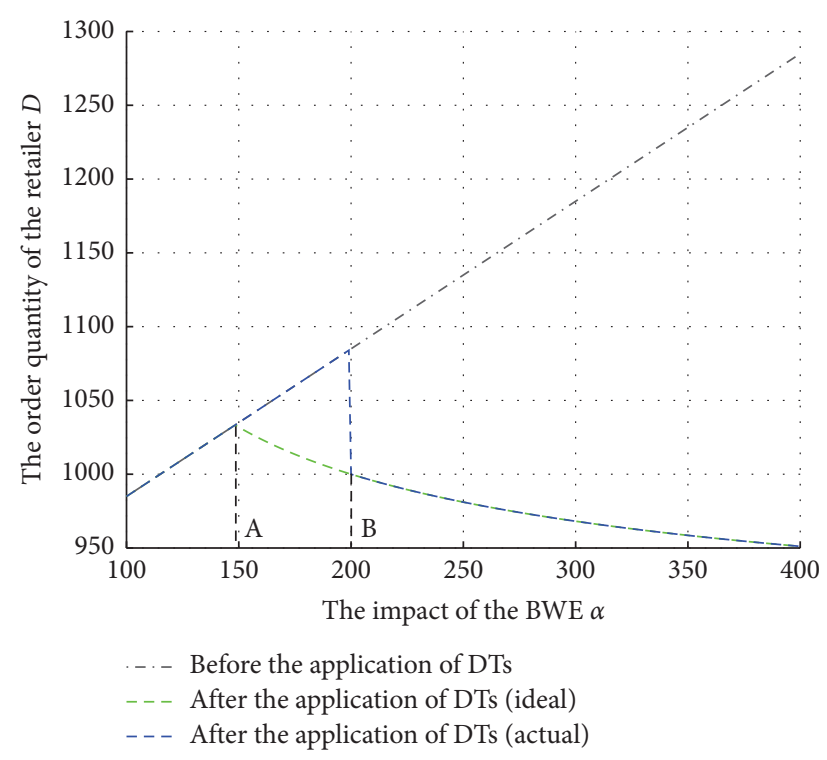

FIGURE 7: Impact of the BWE on retailer's order quantity $(\sigma=100)$.

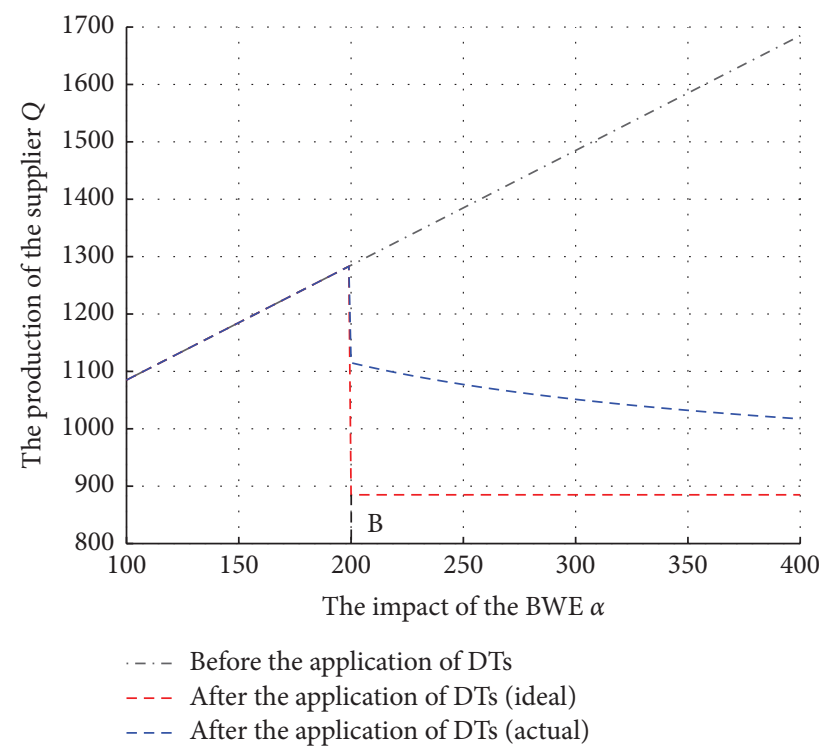

FIgURE 8: Impact of the BWE on supplier's production $(\sigma=100)$.

supply chain will be lower than decentralized decision-making. Figure 14 also shows that only when the BWE is larger, the application of DTs in the supply chain will be higher.

Combining Figures 7, 8, and 14, we find that the retailer's order quantity and supplier's production quantity have decreased under the centralized decision-making scenario, which is mainly due to the reduction of the BWE. After adopting DTs, the order quantity and production quantity have further decreased. The above shows that it is still necessary to adopt DTs after satisfying certain conditions under a centralized decision-making scenario.

Combining Figures 11, 12, and 15, we find that the performance of the supply chain improved under a centralized decision-making scenario, which is mainly because the information sharing under a centralized decision-making scenario reduces the impact of the BWE on the supply chain.

\subsection{Comparison and Numerical Analysis of DT Application Level and Profits of the Supply Chain after Coordination}

6.3.1. Cost-Sharing Contract Coordination. Combining Figures $16-19$, we can find that under certain conditions, the cost-sharing contract can achieve SCC. The application degree of DTs will be improved and the supply chain performance will be improved. However, its scope of application is relatively narrow, and the performance improvement after coordination is not perfect. 


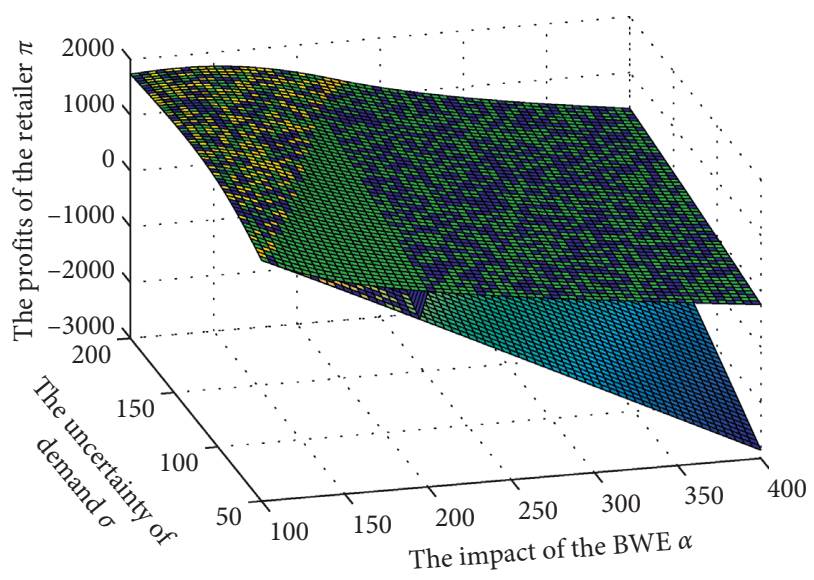

Before the application of DTs

After the application of DTs (actual)

Before the application of DTs (ideal)

FIGURE 9: Impact of DTs on retailer's profits (considering the BWE and stochastic demand).

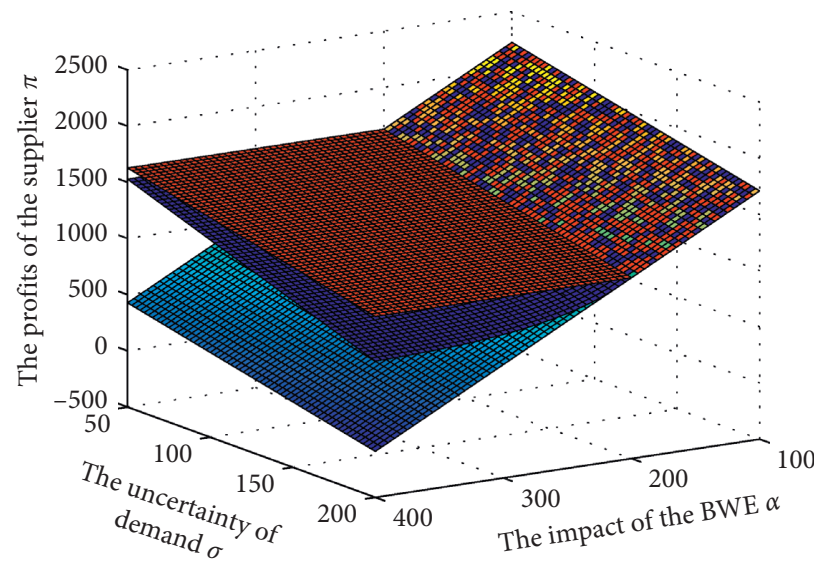

$\square$ Before the application of DTs

After the application of DTs (actual)

After the application of DTs (ideal)

Figure 10: Impact of DTs on supplier's profits (considering the BWE and stochastic demand).

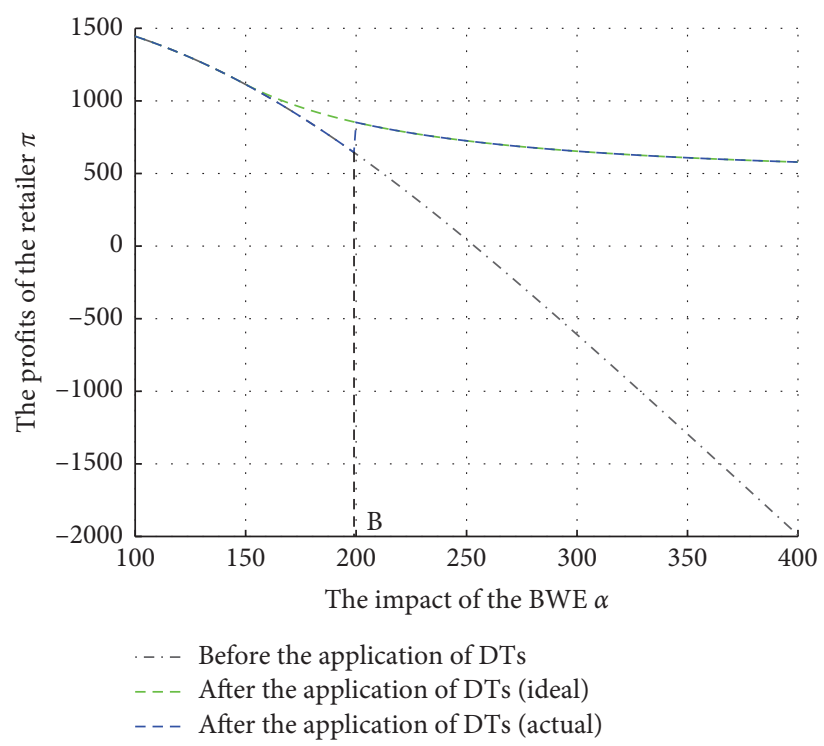

FIgURE 11: Impact of DTs on retailer's profits $(\sigma=100)$. 


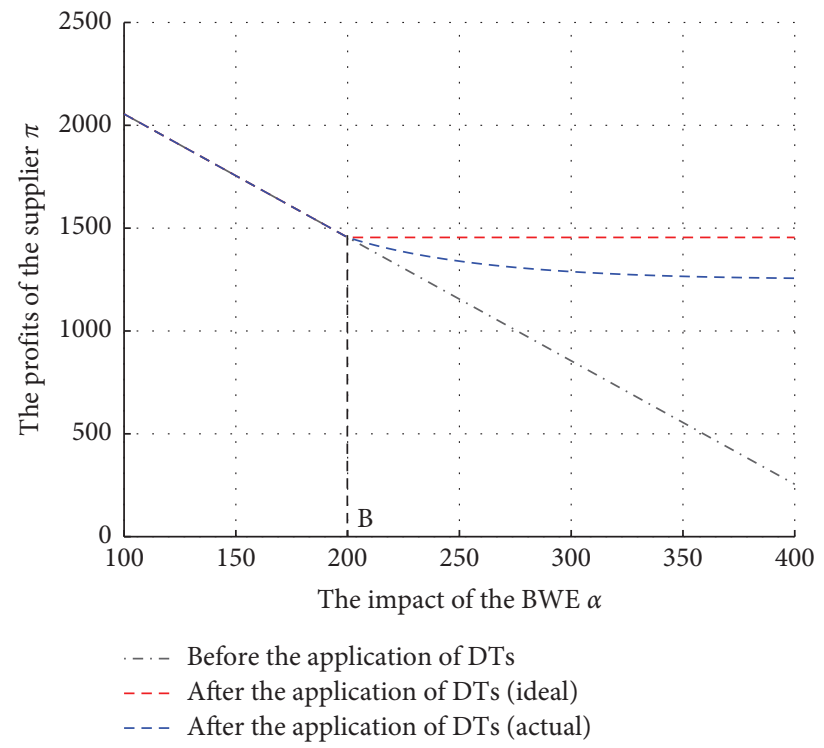

Figure 12: Impact of DTs on supplier's profits $(\sigma=100)$.

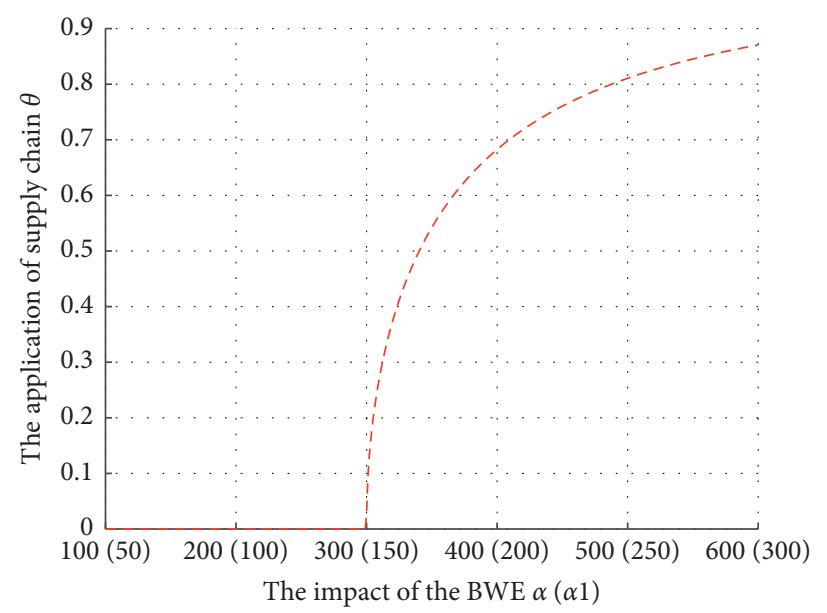

- - - The application level of DTs of supply chain

Figure 13: The BWE on the application of DTs under supply chain $(\sigma=100)$.

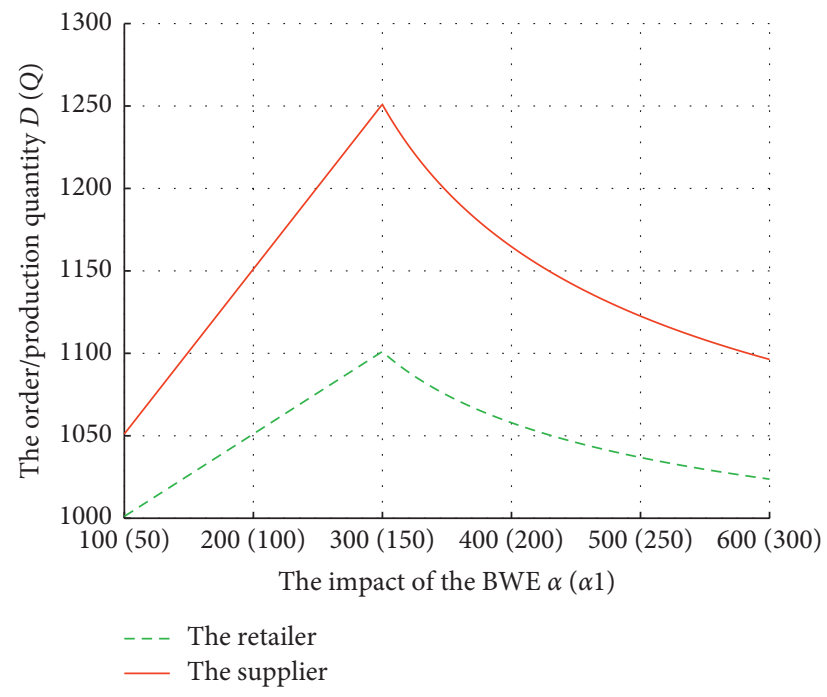

FIgURE 14: The impact of the BWE on retailer's order and supplier's production under centralized decision-making $(\sigma=100)$. 


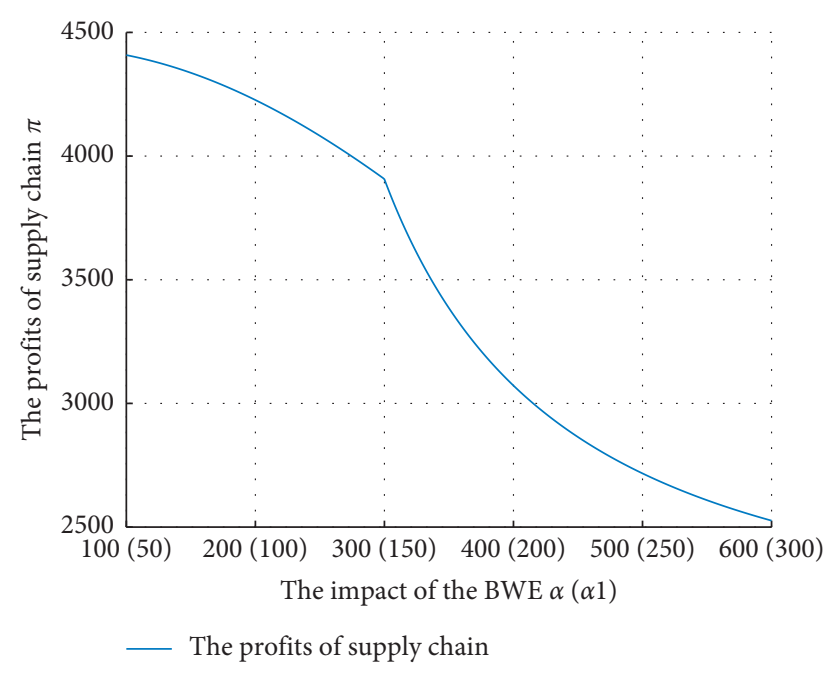

Figure 15: The impact of DTs on supply chain profits $(\sigma=100)$.

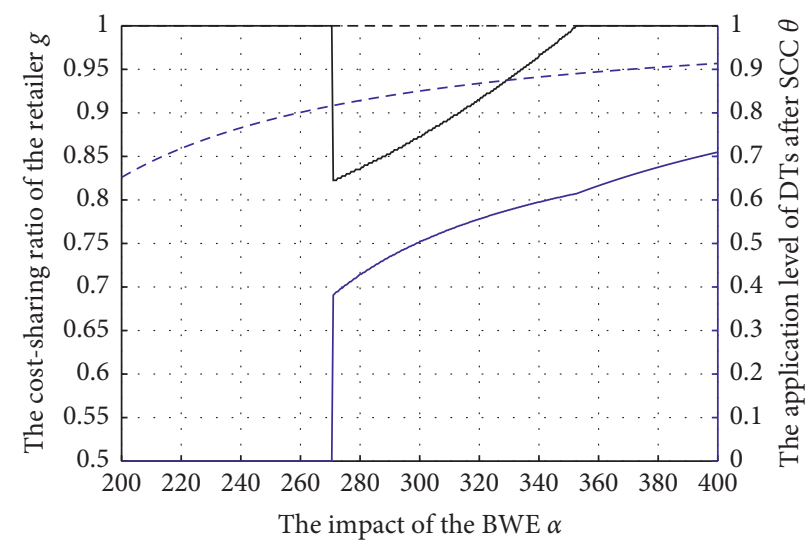

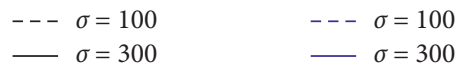

Figure 16: The DT application level and cost-sharing ratio of the retailer under cost-sharing contract (after point B).

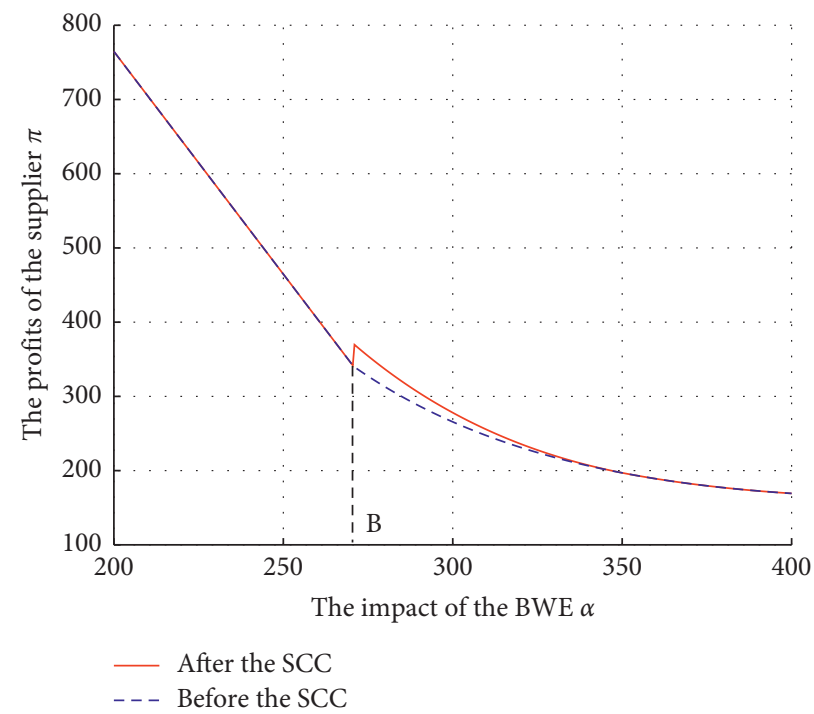

FIGURE 17: The change of the supplier's profits under the cost-sharing contract (after point (B), $\sigma=300$ ). 


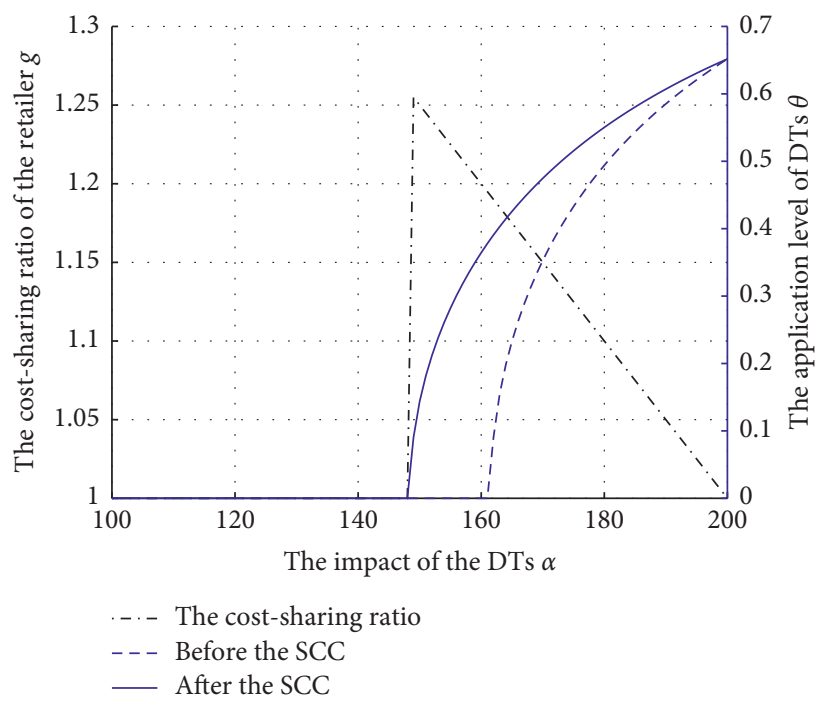

Figure 18: The DT application level and cost-sharing ratio of the retailer under the cost-sharing contract (before point $\mathrm{B}, \sigma=100$ ).

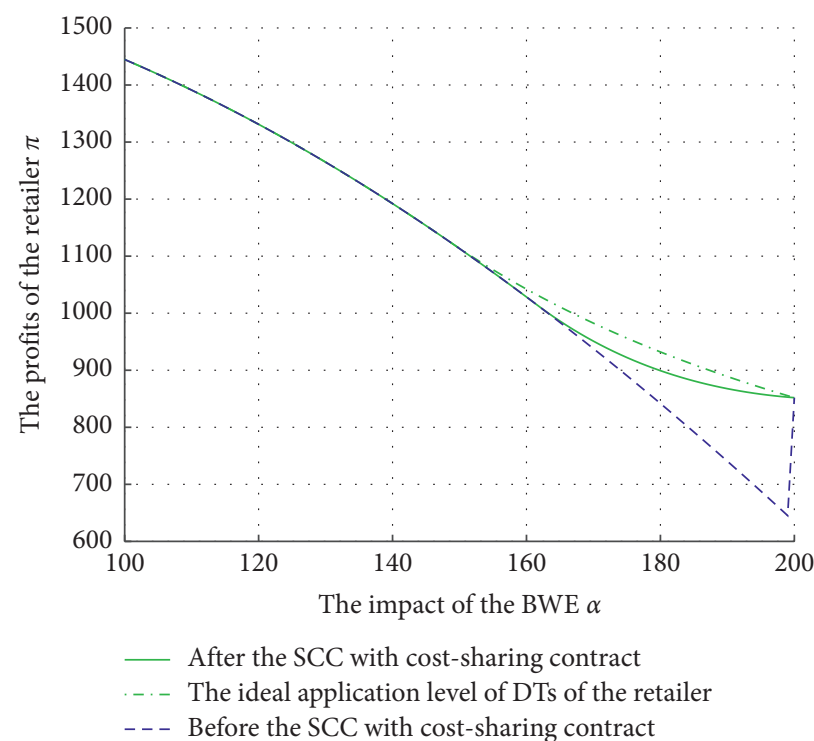

Figure 19: The change of the retailer's profits under the cost-sharing contract (before point (B), $\sigma=100$ ).

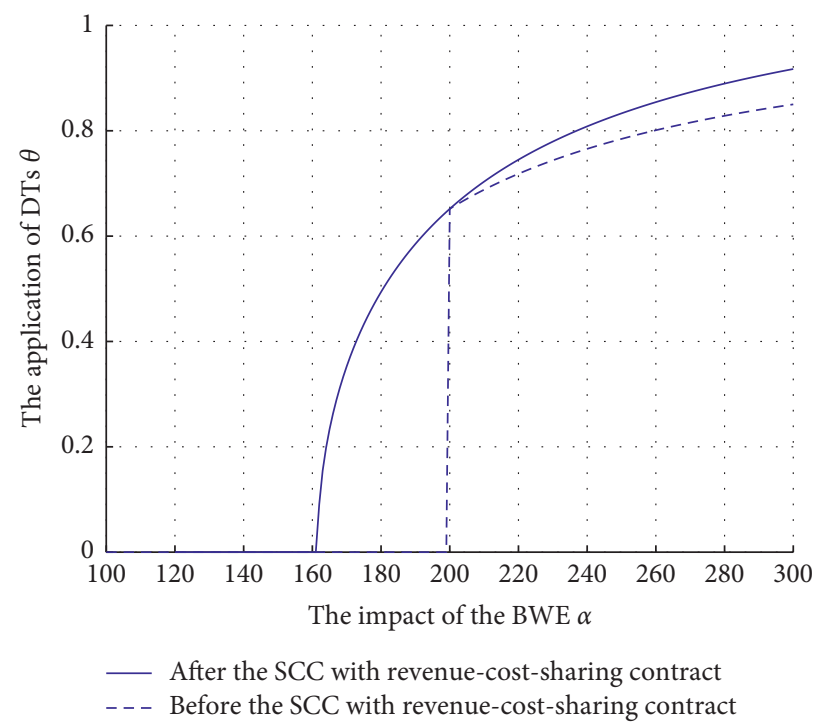

Figure 20: The application level of DTs under the revenue-cost-sharing contract $(\sigma=100)$. 


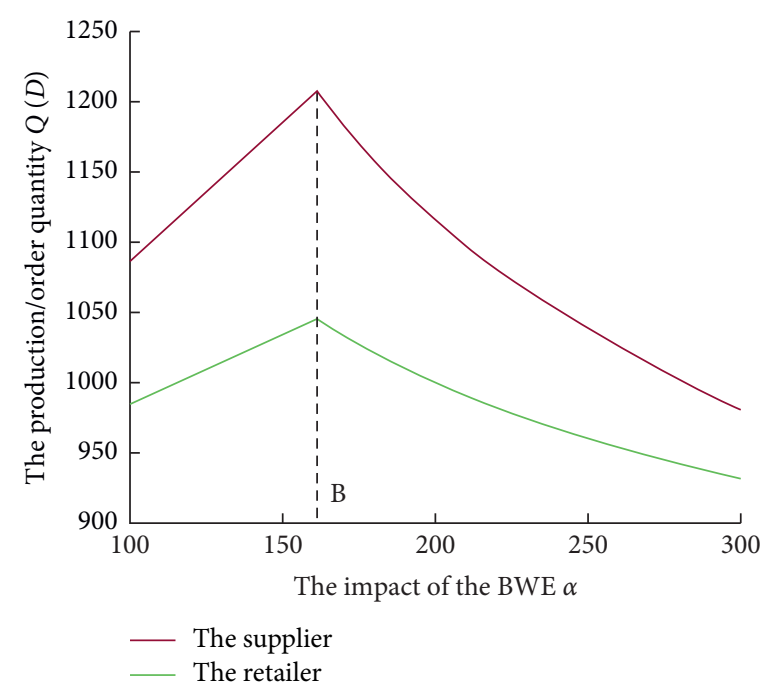

FIGURE 21: The retailer's order and supplier's production under the revenue-cost-sharing contract $(\sigma=100)$.

This is mainly because the application cost of DTs is relatively high, especially for the party who expects a higher $\theta$, although he can encourage the other party to improve $\theta$ by taking part of the cost for the other party. Nevertheless, in some cases, the cost he bears will exceed the benefit he obtains. Obviously, he is not willing to cooperate at this time.

6.3.2. Revenue-Cost-Sharing Contract Coordination. After the introduction of a cost-sharing contract to coordinate the supply chain, the application level of DTs in the supply chain has improved and the profits of all stakeholders in the supply chain have increased. This shows that Pareto improvement has been achieved. We also need to note that before point $\mathrm{B}$, supplier's profits increased more, whereas after point $\mathrm{B}$, the retailer's benefited more. Meanwhile, the application level of DTs has not reached the ideal level. Accordingly, we introduce the revenue-cost- sharing contract, i.e., based on cost-sharing, the party who gains more "returns" to the other party in order to encourage him/her to improve the application level of DTs further to achieve Pareto improvement.

Combining Figures 16 and 20, we find that the application level of DTs in the supply chain has significantly improved after introducing the revenue-cost-sharing contract. Meanwhile, we can find that when $\sigma=100$, the costsharing contract does not work; that is, coordination cannot be achieved, but the revenue-cost-sharing contract can be achieved. The above also proves that the latter has a wider range of use than the former.

Combining Figures 7, 8, and 21, we find that both the retailer's order and the supplier's production quantity have been further reduced (in the coordination range, the value of $a$ in Figure 21 is between 160 and 200). The above shows that the revenue-cost-sharing contract can effectively motivate them, which further proves that the revenue-cost-sharing contract has a broader scope of application than the costsharing contract.

Figures 13 and 22-24 show that when $\sigma=100$, the supplier is willing to use the revenue-cost-sharing contract

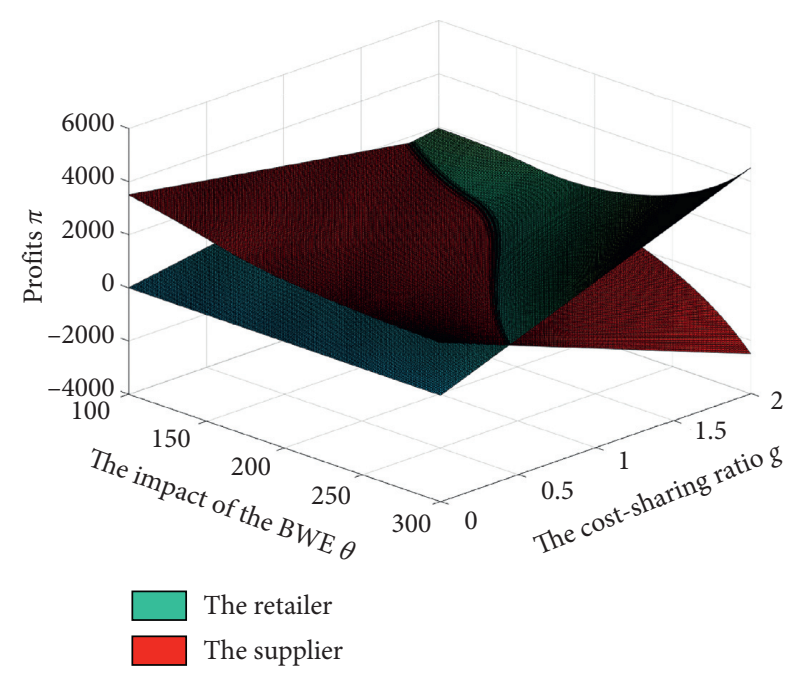

Figure 22: The profits of each stakeholder under the revenue-costsharing contract without consideration of reservation profits $(\sigma=100)$.

rather than the cost-sharing contract. Through Figures 23 and 24, we can find that the scope of SCC is broader after introducing the revenue-cost-sharing contract.

Combining Figures 20-24 and comparing with costsharing contract, the coordination effect of revenue-costsharing contract is better. After adopting the latter contract, $\theta$ in the supply chain will be higher, the order quantity/ production volume will be closer to the actual demand, the profits of both parties will be increased, and the scope of coordination will be wider.

This is mainly because in the revenue-cost-sharing contract, the party with lower $\theta$ will actively subsidize the other party. With the improvement of $\theta$, both sides can gain more profits.

The above shows that under DTs, it is feasible to adopt the revenue-cost-sharing contract to coordinate the supply chain considering both the BWE and uncertain demand. 


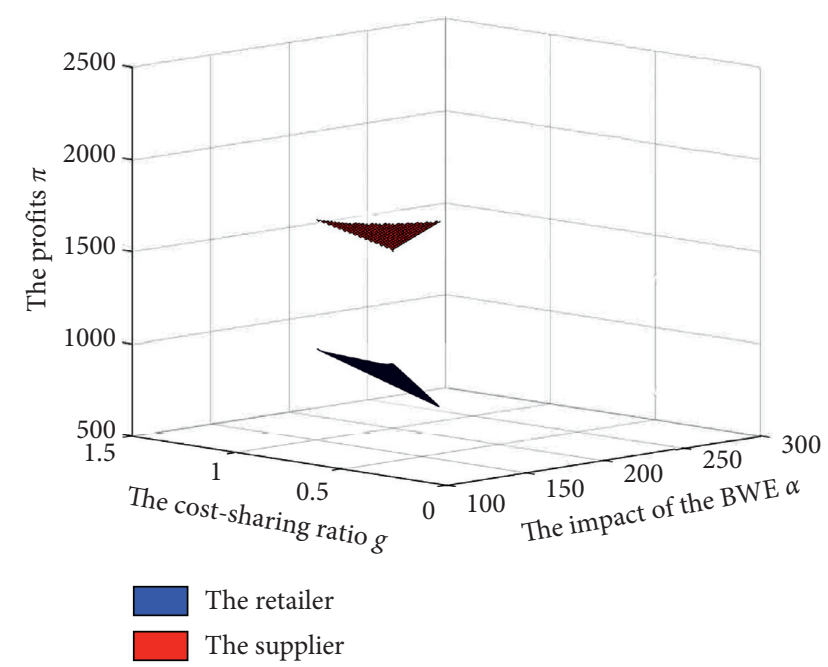

FIgURE 23: The profits of each stakeholder under the revenue-costsharing contract considering reservation profits $(\sigma=100)$.

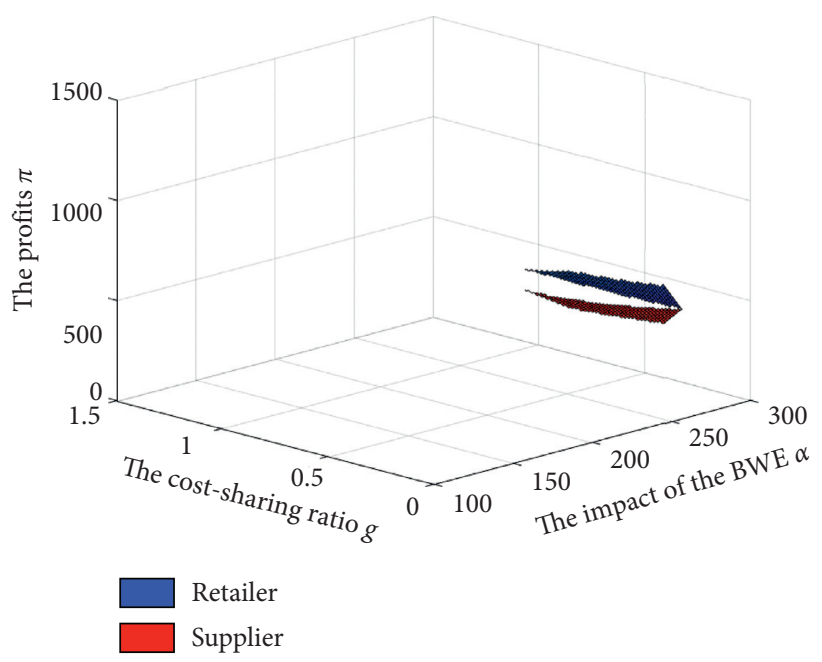

Figure 24: The profits of each stakeholder under the revenue-costsharing contract considering reservation profits $(\sigma=300)$.

Compared with the cost-sharing contract, the revenue-costsharing contract can achieve Pareto improvement.

\section{Conclusions}

In this paper, we construct a model composed of a single supplier and a single retailer and design the corresponding SCC mechanism. We introduce the BWE and stochastic demand into the model under DTs, which are ignored in the existing literature of SCC but have real-life significance for supply chain operation. We study the order quantity, product quantity, and profits of supply chain members under the impact of DTs. The optimal application level of DTs for the retailer and the supplier is proposed, considering the BWE and random demand. Finally, we introduce a costsharing contract and revenue-cost-sharing contract to coordinate the supply chain. Model analysis shows that both SCC contracts can achieve Pareto improvement. Meanwhile, the application scope of the revenue-cost-sharing contract is wider. When it is used to coordinate the supply chain, the application level of DTs in the supply chain is higher, the order quantity of the retailer and the production quantity of the supplier are lower and the profits of the retailer and the supplier are higher than those before the SCC.

The conclusions of our study answer, but are not limited to, the questions raised in the Introduction section: (i) before SCC, the retailer and supplier wish that the application level of DTs is different. The premise of cooperation in adopting DTs is the result of commercial compromise. (ii) After application DTs, the retailer's order quantity and the supplier's production quantity will decrease; that is to say, this will be closer to the actual demand of the real market, and the profits of all stakeholders in the supply chain will increase. Simultaneously, the risk and the BWE will decrease. (iii) After SCC, the order quantity of the retailer and the production quantity of the supplier are further reduced, the application level of DTs improved more, and the profits of stakeholders are increased. (iv) The revenue-cost-sharing contract can achieve Pareto improvement better than a costsharing contract. In the case that the total cost of DTs has not changed, the former can make the application level of DTs in the supply chain higher; the profits increase of each stakeholder in the supply chain is prominent. (v) After SCC, profits distribution is related to the bargaining power of supply chain stakeholders. When one party is in the leading position, he can adjust the proportion of revenue share so that the following party can only obtain reservation profits.

There are some practical insights provided for managers. In a certain range (which is affected by the BWE, the uncertainty of market demand, and the additional cost brought by DTs), the application of DTs can reduce the cost and improve the profits of all stakeholders in the supply chain. The application of higher DTs can reduce the impact of the BWE in a broader range but increase the production cost. SCC plays an essential role in improving the application of DTs, increasing supply chain profits, and reducing unnecessary extra output/order. Therefore, how to develop a more effective SCC mechanism is worth considering. In our conclusions, the impact of DTs on the supply chain is mainly achieved by reducing the BWE, so it may not be wise to adopt a higher application level of DTs blindly and in some cases. For example, when the BWE is small and the cost of DTs is high, relatively, the higher application of DTs can even make the whole supply chain worse. Besides, the stakeholders in the supply chain should also pay attention to the apparent fact of how to minimize the uncertainty of market demand that is conducive to improving the profits of the supply chain.

Our research brings two main novelties to the literature: (i) We coordinate the supply chain with the BWE and stochastic demand under DTs so that the proposed model can be integral and closer to the practical situation of business operation. In this situation, it is of real-life importance to analyze DT application strategies and quantity decisions of stakeholders in the supply chain. (ii) Compared with previous studies, we combine a revenue-sharing contract with a cost-sharing contract to revenue-cost- sharing contract to study SCC issue.

The presented model also includes a few limitations. For instance, there are many strict constraints for the model, 
including considering only one supplier and one retailer and the supplier facing a fixed market. Based on the fact that the retailer is motivated to exaggerate their private forecast information to ensure adequate supply and respond to changes in demand, we assume that there is no shortage between the supplier and retailer in the model. Further studies should consider some interesting extension to this work, such as the more complex supply chain model structure, more generalized hypothesis of the BWE.

\section{Appendix}

\section{A. Retailer's Optimal Decision Solution under Decentralized Decision-Making}

Retailer's enlarged profits are as follows:

$$
E\left(\pi_{r}^{d}\right)=\left(p_{r}-p_{s}-c_{r}\right) D^{d}-\left(p_{r}-v\right) \int_{t}^{D^{d}} F(y-t) \mathrm{d} y-\lambda\left(\theta_{r}^{d}\right)^{2}
$$

where $t=\left(1-\left(\theta_{r}^{d}\right)^{2}\right) \alpha$.
For retailers, profit maximization is the goal when deciding order quantity. The first and second derivatives of expected benefits on the order quantity are as follows, respectively:

$$
\left\{\begin{array}{l}
\frac{\mathrm{d} E\left(\pi_{r}^{d}\right)}{\mathrm{d} D^{d}}=\left(p_{r}-p_{s}-c_{r}\right)-\left(p_{r}-v\right) F\left(D^{d}-t\right), \\
\frac{\mathrm{d}^{2} E\left(\pi_{r}^{d}\right)}{\mathrm{d} D^{d 2}}=-\left(p_{r}-v\right) f\left(D^{d}-t\right) .
\end{array}\right.
$$

Obviously, according to the second derivative, we know that there is a maximum value of the function. According to the first-order condition, we can obtain the following:

$$
D^{d *}=F^{-1}\left(\frac{p_{r}-p_{s}-c_{r}}{p_{r}-v}\right)+t
$$

Retailer's real expected profits and the first and second derivatives of it on application level of DTs are as follows, respectively:

$$
\begin{gathered}
\pi_{r}^{*}=\left(p_{r}-p_{s}-c_{r}\right) D^{d *}-\left(p_{r}-v\right) \int_{0}^{D^{d *}} F(x) \mathrm{d} x-\lambda\left(\theta_{r}^{d}\right)^{2} . \\
\left\{\begin{array}{l}
\frac{\mathrm{d} E\left(\pi_{r}^{d}\right)}{\mathrm{d}\left(\theta_{r}^{d}\right)}=-2\left(\theta_{r}^{d}\right) \alpha\left(p_{r}-p_{s}-c_{r}\right)+2\left(\theta_{r}^{d}\right) \alpha\left(p_{r}-v\right) F\left(D^{d *}\right)-2 \lambda\left(\theta_{r}^{d}\right), \\
\frac{\mathrm{d}^{2} E\left(\pi_{r}^{d}\right)}{\mathrm{d}\left(\theta_{r}^{d}\right)^{2}}=-2 \alpha\left(p_{r}-p_{s}-c_{r}\right)-2 \lambda-4\left(\theta_{r}^{d}\right)^{2} \alpha^{2}\left(p_{r}-v\right) f\left(D^{d *}\right)+2 \alpha\left(p_{r}-v\right) F\left(D^{d *}\right) .
\end{array}\right.
\end{gathered}
$$

According to the first-order condition, the optimal application level of DTs is as follows:

$$
\theta_{r}^{d *}=\sqrt{1-\frac{F^{-1}\left(\left(p_{r}-p_{s}-c_{r} / p_{r}-v\right)+\left(\lambda / \alpha\left(p_{r}-v\right)\right)\right)-F^{-1}\left(p_{r}-p_{s}-c_{r} / p_{r}-v\right)}{\alpha}}
$$

The optimal order quantity can obtain by substituting (A.6) into (A.3):

$$
D^{d *}=F^{-1}\left(\frac{p_{r}-p_{s}-c_{r}}{p_{r}-v}+\frac{\lambda}{\alpha\left(p_{r}-v\right)}\right) \text {. }
$$

Because the existence of extremum of function is not discussed by using the second derivative condition, we can obtain the second derivative by substituting (A.7) into (A.5):

$$
\frac{\mathrm{d}^{2} E\left(\pi_{r}^{d}\right)}{\mathrm{d}\left(\theta_{r}^{d}\right)^{2}}=-4\left(\theta_{r}^{d}\right)^{2} \alpha f\left(D^{d *}\right)<0
$$

Through the verification of (A.8), we can find that the order quantity and the application level of DTs obtained by (A.6) and (A.7) are the best decision-making of the retailer.

\section{B. The Solution to the Supplier's Optimal Decision under Decentralized Decision-Making}

Expected revenue of supplier after "enlargement" is as follows:

$$
E\left(\pi_{s}^{d}\right)=p_{s} D^{d *}-c_{s} Q^{d *}+v\left(Q^{d *}-D^{d *}\right)-\lambda\left(\theta_{s}^{d}\right)^{2},
$$

where $Q^{d *}=D^{d *}+\left(1-\left(\theta_{s}^{d}\right)^{2}\right) \alpha$.

The first and second derivatives of supplier's expected profits on the application level of DTs are 


$$
\left\{\begin{array}{l}
\frac{\mathrm{d} E\left(\pi_{s}^{d}\right)}{\mathrm{d} \theta_{s}^{d}}=2 \theta_{s}^{d}\left(-\alpha p_{s}+2 \alpha c_{s}-\alpha v-\lambda\right) \\
\frac{\mathrm{d}^{2} E\left(\pi_{s}^{d}\right)}{\mathrm{d}\left(\theta_{s}^{d}\right)^{2}}=-2 \alpha p_{s}+4 \alpha c_{s}-2 \alpha v-2 \lambda
\end{array}\right.
$$

where $\quad \mathrm{d}^{2} E\left(\pi_{s}^{d}\right) / \mathrm{d}\left(\theta_{s}^{d}\right)^{2}=--2 \alpha p_{s}+4 \alpha c_{s}-2 \alpha v-2 \lambda<0$; that is, when $-p_{s}+2 c_{s}-v<(\lambda / \alpha)$, there is a maximal value of supplier's expected profits, that is, $\theta_{s}^{d} *=0$. When $\mathrm{d}^{2} E\left(\pi_{s}^{d}\right) / \mathrm{d}\left(\theta_{s}^{d}\right)^{2}=-2 \alpha p_{s}+4 \alpha c_{s}-2 \alpha v-2 \lambda>0$, there is a minimal value of the supplier's expected profits. According to the boundary conditions, we can obtain $\theta_{s}^{d *}=1$, that is,

$$
\left\{\begin{array}{l}
-p_{s}+2 c_{s}-v<\frac{\lambda}{\alpha}, \theta_{s}^{d *}=0 \\
-p_{s}+2 c_{s}-v>\frac{\lambda}{\alpha}, \theta_{s}^{d *}=1
\end{array}\right.
$$

\section{Retailer's Optimal Decision Solution under Cost-Sharing Coordination}

(1) When $-p_{s}+2 c_{s}-v>(2-g) \lambda / \alpha$, the profits of the retailer after coordination of the supply chain with the cost-sharing contract are as follows:

$$
\begin{aligned}
E\left(\pi_{r}^{\mathrm{cs}}\right)= & \left(p_{r}-p_{s}-c_{r}\right) D^{\mathrm{cs}}-\left(p_{r}-v\right) \\
& \cdot \int_{\left(1-\left(\theta_{r}^{\mathrm{cs}}\right)^{2}\right) \alpha}^{D^{\mathrm{cs}}} F\left(y-\left(1-\left(\theta_{r}^{\mathrm{cs}}\right)^{2}\right) \alpha\right) \mathrm{d} y-g \lambda\left(\theta_{r}^{\mathrm{cs}}\right)^{2},
\end{aligned}
$$

where $0 \leq g \leq 1$, and it means that the supplier undertakes a portion of the cost for the retailer.

The first and second derivatives of the retailer's expected profits on the order quantity are as follows, respectively:

$$
\left\{\begin{array}{l}
\frac{\mathrm{d} E\left(\pi_{r}^{c s}\right)}{\mathrm{d} D^{c s}}=\left(p_{r}-p_{s}-c_{r}\right)-\left(p_{r}-v\right) F\left(D^{c s}-\left(1-\left(\theta_{r}^{c s}\right)^{2}\right) \alpha\right), \\
\frac{\mathrm{d}^{2} E\left(\pi_{r}^{\mathrm{cs}}\right)}{\mathrm{d} D^{c s 2}}=-\left(p_{r}-v\right) f\left(D^{\mathrm{cs}}-\left(1-\left(\theta_{r}^{\mathrm{cs}}\right)^{2}\right) \alpha\right) .
\end{array}\right.
$$

There exists an optimal solution for the function. According to the first-order condition, the optimal order quantity of the retailer can be obtained as follows:

$$
D^{\mathrm{cs} *}=F^{-1}\left(\frac{p_{r}-p_{s}-c_{r}}{p_{r}-v}\right)+\left(1-\left(\theta_{r}^{\mathrm{cs}}\right)^{2}\right) \alpha .
$$

As mentioned above, the retailer determines the application level of DTs based on real profits:

$$
\begin{aligned}
E\left(\pi_{r}^{\mathrm{cs}}\right)= & \left(p_{r}-p_{s}-c_{r}\right) D^{\mathrm{cs} *} \\
& -\left(p_{r}-v\right) \int_{0}^{D^{c s *}} F(x) \mathrm{d} x-g \lambda\left(\theta_{r}^{c s}\right)^{2}
\end{aligned}
$$

The first and second derivatives of retailer's expected profits on the application level of DTs are as follows, respectively:

$$
\left\{\begin{array}{l}
\frac{\mathrm{d} E\left(\pi_{r}^{\mathrm{cs}}\right)}{\mathrm{d} \theta_{r}^{\mathrm{cs}}}=-2 \theta_{r}^{\mathrm{cs}}\left(\alpha\left(p_{r}-p_{s}-c_{r}\right)+\alpha\left(p_{r}-v\right) F\left(D^{\mathrm{cs} *}\right)-g \lambda\right) \\
\frac{\mathrm{d}^{2} E\left(\pi_{r}^{\mathrm{cs}}\right)}{\mathrm{d}\left(\theta_{r}^{\mathrm{cs}}\right)^{2}}=-2 \alpha\left(p_{r}-p_{s}-c_{r}\right)+2 \alpha\left(p_{r}-v\right) F\left(D^{\mathrm{cs} *}\right)-4 \theta^{2} \alpha^{2}\left(p_{r}-v\right) f\left(D^{\mathrm{cs} *}\right)-2 g \lambda .
\end{array}\right.
$$

According to the first-order condition, we can obtain the following:

$$
\left\{\begin{array}{l}
\theta_{r}^{\mathrm{cs} *}=\sqrt{1-\frac{F^{-1}\left(\left(p_{r}-p_{s}-c_{r} / p_{r}-v\right)+g \lambda / \alpha\left(p_{r}-v\right)\right)-F^{-1}\left(p_{r}-p_{s}-c_{r} / p_{r}-v\right)}{\alpha}} \\
D^{\mathrm{cs} *}=F^{-1}\left(\frac{p_{r}-p_{s}-c_{r}}{p_{r}-v}+\frac{g \lambda}{\alpha\left(p_{r}-v\right)}\right)
\end{array}\right.
$$

Because the existence of maximum value of function id not discussed by using the second derivative condition, we can check it by substituting (C.6) into the second derivative:

$$
\frac{\mathrm{d}^{2} E\left(\pi_{r}^{\mathrm{cs}}\right)}{\mathrm{d}\left(\theta_{r}^{c s}\right)^{2}}=-4\left(\theta_{r}^{\mathrm{cs}}\right)^{2} \alpha^{2}\left(p_{r}-v\right) f\left(D^{\mathrm{cs} *}\right)<0
$$

Equation (C.6) is the optimal solution. 


\section{Retailer and Supplier's Optimal \\ Decisions under Revenue-Cost- Sharing Contract}

In this case, the profits of the retailer are as follows:

$$
E\left(\pi_{r}^{\mathrm{rcs}}\right)=h\left[\left(p_{r}-p_{s}-c_{r}\right) D^{\mathrm{rcs}}-\left(p_{r}-v\right) \int_{\left(1-\left(\theta_{r}^{\mathrm{rcs}}\right)^{2}\right) \alpha}^{D_{\mathrm{rcs}}} F\left(y-\left(1-\left(\theta_{r}^{\mathrm{rcs}}\right)^{2}\right) \alpha\right) \mathrm{d} y\right]-g \lambda\left(\theta_{r}^{\mathrm{rcs}}\right)^{2} .
$$

The first and second derivatives of the retailer's expected profits on the order quantity are as follows, respectively:

$$
\left\{\begin{array}{l}
\frac{\mathrm{d} E\left(\pi_{r}^{\mathrm{rcs}}\right)}{\mathrm{d} D^{\mathrm{rcs}}}=h\left(p_{r}-p_{s}-c_{r}\right)-h\left(p_{r}-v\right) F\left(D^{\mathrm{rcs}}-\left(1-\left(\theta_{r}^{\mathrm{rcs}}\right)^{2}\right) \alpha\right), \\
\frac{\mathrm{d}^{2} E\left(\pi_{r}^{\mathrm{rcs}}\right)}{\mathrm{d} D^{r c s}}=-h\left(p_{r}-v\right) F\left(D^{\mathrm{rcs}}-\left(1-\left(\theta_{r}^{\mathrm{rcs}}\right)^{2}\right) \alpha\right) .
\end{array}\right.
$$

As mentioned above, the retailer determines the application level of DTs based on real profits $E\left(\pi_{r}\right)$ :

$$
\begin{aligned}
E\left(\pi_{r}^{\mathrm{rcs}}\right)= & h\left[\left(p_{r}-p_{s}-c_{r}\right) D^{\mathrm{rcs} *}-\left(p_{r}-v\right) \int_{0}^{D^{\mathrm{rcs} *}} F(x) \mathrm{d} x\right] \\
& -g \lambda\left(\theta_{r}^{\mathrm{rcs}}\right)^{2} .
\end{aligned}
$$

The function has a maximum value. According to the first-order condition, the optimal order quantity of the retailer is as follows:

$$
D^{\mathrm{rcs} *}=F^{-1}\left(\frac{p_{r}-p_{s}-c_{r}}{p_{r}-v}\right)+\left(1-\left(\theta_{r}^{\mathrm{rcs}}\right)^{2}\right) \alpha .
$$

The first and second derivatives of retailer's expected profits on the application level of DTs are as follows, respectively:

$$
\left\{\begin{array}{l}
\frac{\mathrm{d} E\left(\pi_{r}^{\mathrm{rcs}}\right)}{\mathrm{d} \theta_{r}^{\mathrm{rcs}}}=2 \theta_{r}^{\mathrm{rcs}}\left(h\left(-\alpha\left(p_{r}-p_{s}-c_{r}\right)+\alpha\left(p_{r}-v\right) F\left(D^{\mathrm{rcs} *}\right)\right)-g \lambda\right) \\
\frac{\mathrm{d}^{2} E\left(\pi_{r}^{\mathrm{rcs}}\right)}{\mathrm{d}\left(\theta_{r}^{\mathrm{rcs}}\right)^{2}}=h\left(-2 \alpha\left(p_{r}-p_{s}-c_{r}\right)+2 \alpha\left(p_{r}-v\right)\left(F\left(D^{\mathrm{rcs} *}\right)-2 \theta^{2} \alpha f\left(D^{\mathrm{rcs} *}\right)\right)\right)-2 g \lambda
\end{array}\right.
$$

According to the first-order condition, it can be obtained that

$$
\left\{\begin{array}{l}
\theta_{r}^{\mathrm{rcs} *}=\sqrt{1-\frac{F^{-1}\left(\left(p_{r}-p_{s}-c_{r} / p_{r}-v\right)+\left(g \lambda / \alpha h\left(p_{r}-v\right)\right)\right)-F^{-1}\left(p_{r}-p_{s}-c_{r} / p_{r}-v\right)}{\alpha}} \\
D^{\mathrm{rcs} *}=F^{-1}\left(\frac{p_{r}-p_{s}-c_{r}}{p_{r}-v}+\frac{g \lambda}{\alpha h\left(p_{r}-v\right)}\right)
\end{array}\right.
$$

Verifying by substituting (D.6) into the second derivative, it can be concluded that

$$
\frac{\mathrm{d}^{2} E\left(\pi_{r}^{\mathrm{rcs}}\right)}{\mathrm{d}\left(\theta_{r}^{\mathrm{rcs}}\right)^{2}}=-2 g \lambda(1-h)-4 h\left(\theta_{r}^{\mathrm{rcs}}\right)^{2} \alpha^{2}\left(p_{r}-v\right) f\left(D^{\mathrm{rcs} *}\right)<0 .
$$

$$
\begin{aligned}
E\left(\pi_{s}^{\mathrm{rcs}}\right)= & (1-h) E\left(R^{*}\right)+p_{s} D^{\mathrm{rcs} *} \\
& -c_{s} Q^{\mathrm{rcs}} v\left(Q^{\mathrm{rcs}}-D^{\mathrm{rcs} *}\right)-(2-g) \lambda \theta_{s}^{r c s 2}
\end{aligned}
$$

where

Equation (D.6) is the optimal solution.

Thus, the profits of the supplier are as follows: 


$$
\left\{\begin{array}{l}
Q^{\mathrm{rcs}}=D^{\mathrm{rcs} *}+\left(1-\theta_{s}^{\mathrm{rcs} 2}\right) \alpha, \\
E\left(R^{*}\right)=\left(p_{r}-p_{s}-c_{r}\right) D^{\mathrm{rcs} *}-\left(p_{r}-v\right) \int_{0}^{D^{\mathrm{rcs} *}} F(x) \mathrm{d} x .
\end{array}\right.
$$

The first and second derivatives of supplier's expected profits on the application level of DTs are as follows, respectively:

$$
\left\{\begin{array}{l}
\frac{\mathrm{d} E\left(\pi_{s}^{\mathrm{rcs}}\right)}{\mathrm{d} \theta_{s}^{\mathrm{rcs}}}=(1-h) A-2 \theta_{s}^{\mathrm{rcs}}\left(\alpha p_{s}-2 \alpha c_{s}+\alpha v+(2-g) \lambda\right), \\
\frac{\mathrm{d}^{2} E\left(\pi_{s}^{\mathrm{rcs}}\right)}{\mathrm{d}\left(\theta_{s}^{\mathrm{rcs}}\right)^{2}}=(1-h) B-2 \alpha\left(p_{s}-2 c_{s}+v\right)-(4-2 g) \lambda,
\end{array}\right.
$$

where

$$
\left\{\begin{aligned}
A= & -2 \theta_{s}^{\mathrm{rcs}} \alpha\left(p_{r}-p_{s}-c_{r}\right)+2 \theta_{s}^{\mathrm{rcs}} \alpha\left(p_{r}-v\right) F\left(D^{\mathrm{rcs} *}\right), \\
B= & -2 \alpha\left(p_{r}-p_{s}-c_{r}\right)+2 \alpha\left(p_{r}-v\right) \\
& \times\left(F\left(D^{\mathrm{rcs} *}\right)-2\left(\theta_{s}^{\mathrm{rcs}}\right)^{2} \alpha f\left(D^{\mathrm{rcs} *}\right)\right) .
\end{aligned}\right.
$$

According to the first and second derivatives, the application level of DTs that supplier wishes, the order quantity of retailer, and the production quantity of supplier are as follows, respectively:

$$
\left\{\begin{array}{l}
\theta_{s}^{\mathrm{rcs} *}=\sqrt{1-\frac{D^{\mathrm{rcs} *}-F^{-1}\left(p_{r}-p_{s}-c_{r} / p_{r}-v\right)}{\alpha}}, \\
Q^{\mathrm{rcs} *}=2 D^{\mathrm{rcs} *}-F^{-1}\left(\frac{p_{r}-p_{s}-c_{r}}{p_{r}-v}\right), \\
D^{\mathrm{rcs} *}=F^{-1}\left(\frac{\alpha\left(p_{s}-2 c_{s}+v\right)+(2-g) \lambda}{\alpha(1-h)\left(p_{r}-v\right)}+\frac{p_{r}-p_{s}-c_{r}}{p_{r}-v}\right) .
\end{array}\right.
$$

By substituting (D.12) into the second derivative conditional, it can be verified that

$$
\frac{\mathrm{d}^{2} E\left(\pi_{s}^{\mathrm{rcs}}\right)}{\mathrm{d}\left(\theta_{s}^{\mathrm{rcs}}\right)^{2}}=-h(4-2 g) \lambda-4(1-h)\left(p_{r}-v\right)\left(\alpha \theta_{s}^{\mathrm{rcs}}\right)^{2} f\left(D^{\mathrm{rcs} *}\right) .
$$

Equation (D.4) is the optimal solution.

\section{Data Availability}

All relevant data are included within the paper.

\section{Conflicts of Interest}

The authors declare that there are no conflicts of interest regarding the publication of this paper.

\section{Acknowledgments}

This work was supported by the National Natural Science Foundation Council of China under project nos. 71661029, 71862035, and 71502159, the Yunnan Fundamental Research Project under grant no. 2019FB085, Scientific Research Foundation Project of Yunnan Education Department under Grant no. 2019J1177, and Key Project of Honghe University under Grant no. HC2019002.

\section{References}

[1] M. Wiedenmann and A. Größler, "The impact of digital technologies on operational causes of the bullwhip effect-a literature review," Procedia CIRP, vol. 81, pp. 552-557, 2019.

[2] A. Y. L. Chong, E. Ch'ng, M. J. Liu, and B. Li, "Predicting consumer product demands via big data: the roles of online promotional marketing and online reviews," International Journal of Production Research, vol. 55, no. 17, pp. 5142-5156, 2017.

[3] H. Treiblmaier, "The impact of the blockchain on the supply chain: a theory-based research framework and a call for action," Supply Chain Management: An International Journal, vol. 23, no. 6, pp. 545-559, 2018.

[4] E. Bottani, R. Montanari, and A. Volpi, "The impact of RFID and EPC network on the bullwhip effect in the Italian FMCG supply chain," International Journal of Production Economics, vol. 124, no. 2, pp. 426-432, 2010.

[5] A. Wright and P. De Filippi, "Decentralized blockchain technology and the rise of lex cryptographia," SSRN Electronic Journal, 2015, https:/www.researchgate.net/publication/ 314892724_Decentralized_Blockchain_Technology_and_the_ Rise_of_Lex_Cryptographia.

[6] IBM, "Blockchain best practices: from 100s of client projects," I.I.f.B. Value, IBM Corporation, Armonk, NY, USA, 2018.

[7] IBM, "Build your trust advantage: leadership in the era of data and AI everywhere," I.I.f.B. Value, IBM Corporation, Armonk, NY, USA, 2019.

[8] IBM, "Maersk and IBM unveil first Industry-wide crossborder supply chain solution on blockchain," I.I.f.B. Value, IBM Corporation, Armonk, NY, USA, 2017.

[9] Y. Fu and J. Zhu, "Big production enterprise supply chain endogenous risk management based on blockchain," IEEE Access, vol. 7, pp. 15310-15319, 2019.

[10] Y. Wang, J. H. Han, and P. Beynon-Davies, "Understanding blockchain technology for future supply chains: a systematic literature review and research agenda," Supply Chain Management: An International Journal, vol. 24, no. 1, pp. 62-84, 2019.

[11] E. Hofmann, "Big data and supply chain decisions: the impact of volume, variety and velocity properties on the bullwhip effect," International Journal of Production Research, vol. 51, no. 17, pp. 5108-5126, 2017.

[12] W. Jiang, "An intelligent supply chain information collaboration model based on Internet of things and big data," IEEE Access, vol. 7, pp. 58324-58335, 2019.

[13] C. Gonul Kochan, D. R. Nowicki, B. Sauser, and W. S. Randall, "Impact of cloud-based information sharing on hospital supply chain performance: a system dynamics framework," International Journal of Production Economics, vol. 195, pp. 168-185, 2018.

[14] Y. Yu, R. Q. Cao, and D. Schniederjans, "Cloud computing and its impact on service level: a multi-agent simulation 
model," International Journal of Production Research, vol. 55, no. 15, pp. 4341-4353, 2017.

[15] E. Hofmann and M. Rüsch, "Industry 4.0 and the current status as well as future prospects on logistics," Computers in Industry, vol. 89, pp. 23-34, 2017.

[16] Y. Zhang, L. Zhao, and C. Qian, "Modeling of an IoT-enabled supply chain for perishable food with two-echelon supply hubs," Industrial Management \& Data Systems, vol. 117, no. 9, pp. 1890-1905, 2017.

[17] S. Zhao and Q. Zhu, "Remanufacturing supply chain coordination under the stochastic remanufacturability rate and the random demand," Annals of Operations Research, vol. 257, no. 1-2, pp. 661-695, 2017.

[18] J. Zhang and J. Chen, "Coordination of information sharing in a supply chain," International Journal of Production Economics, vol. 143, no. 1, pp. 178-187, 2013.

[19] Y. Ma, N. Wang, A. Che, Y. Huang, and J. Xu, "The bullwhip effect under different information-sharing settings: a perspective on price-sensitive demand that incorporates price dynamics," International Journal of Production Research, vol. 51, no. 10, pp. 3085-3116, 2013.

[20] J. Shan, S. Yang, S. Yang, and J. Zhang, "An empirical study of the bullwhip effect in China," Production and Operations Management, vol. 23, no. 4, pp. 537-551, 2014.

[21] R. L. Bray and H. Mendelson, "Information transmission and the bullwhip effect: an empirical investigation," Management Science, vol. 58, no. 5, pp. 860-875, 2012.

[22] E. Hofmann, "Book review," Journal of Purchasing and Supply Management, vol. 19, no. 3, pp. 212-213, 2013.

[23] D. R. Towill, M. M. Naim, and J. Wikner, "Industrial dynamics simulation models in the design of supply chains," International Journal of Physical Distribution \& Logistics Management, vol. 22, no. 5, pp. 3-13, 1992.

[24] J. D. Sterman, "Modeling managerial behavior: misperceptions of feedback in a dynamic decision making experiment," Management Science, vol. 35, no. 3, pp. 321-339, 1989.

[25] P. D. Tai, T. T. H. Duc, and J. Buddhakulsomsiri, "Measure of bullwhip effect in supply chain with price-sensitive and correlated demand," Computers \& Industrial Engineering, vol. 127, pp. 408-419, 2019.

[26] Y. He and J. Zhang, "Random yield supply chain with a yield dependent secondary market," European Journal of Operational Research, vol. 206, no. 1, pp. 221-230, 2010.

[27] B. Hu and Y. Feng, "Optimization and coordination of supply chain with revenue sharing contracts and service requirement under supply and demand uncertainty," International Journal of Production Economics, vol. 183, pp. 185-193, 2017.

[28] L. Xu, R. Gao, Y. Xie, and P. Du, "To be or not to be? big data business investment decision-making in the supply chain," Sustainability, vol. 11, no. 8, pp. 2298-2312, 2019.

[29] P. Liu, "Pricing policies and coordination of low-carbon supply chain considering targeted advertisement and carbon emission reduction costs in the big data environment," Journal of Cleaner Production, vol. 210, pp. 343-357, 2019.

[30] Liu, Li, and Qi, "Research on risk avoidance and coordination of supply chain subject based on blockchain technology," Sustainability, vol. 11, no. 7, p. 14, Article ID 2182, 2019.

[31] Z. Guo, Y. Liu, and Y. Liu, "Coordinating a three level supply chain under generalized parametric interval-valued distribution of uncertain demand," Journal of Ambient Intelligence and Humanized Computing, vol. 8, no. 5, pp. 677694, 2017.

[32] T. Efendigil, S. Önüt, and C. Kahraman, "A decision support system for demand forecasting with artificial neural networks and neuro-fuzzy models: a comparative analysis," Expert Systems with Applications, vol. 36, no. 3, pp. 6697-6707, 2009.

[33] P. Liu and S. P. Yi, "A study on supply chain investment decision-making and coordination in the Big Data environment," Annals of Operations Research, vol. 270, no. 1-2, pp. 235-253, 2018.

[34] P. Liu and S. P. Yi, "Investment decision-making and coordination of a three-stage supply chain considering Data Company in the Big Data era," Annals of Operations Research, vol. 270, no. 1-2, pp. 255-271, 2018.

[35] P. Liu and S. P. Yi, "Investment decision-making and coordination of supply chain: a new research in the big data era," Discrete Dynamics in Nature and Society, vol. 2016, Article ID 2026715, 2016.

[36] S.-J. Wang, C.-T. Huang, W.-L. Wang, and Y.-H. Chen, "Incorporating ARIMA forecasting and service-level based replenishment in RFID-enabled supply chain," International Journal of Production Research, vol. 48, no. 9, pp. 2655-2677, 2010.

[37] S.-J. Wang, W.-L. Wang, C.-T. Huang, and S.-C. Chen, "Improving inventory effectiveness in RFID-enabled global supply chain with Grey forecasting model," The Journal of Strategic Information Systems, vol. 20, no. 3, pp. 307-322, 2011.

[38] M. Ben-Daya, E. Hassini, and Z. Bahroun, "Internet of things and supply chain management: a literature review," International Journal of Production Research, vol. 57, no. 15-16, pp. 4719-4742, 2019.

[39] H. L. Lee, V. Padmanabhan, and S. Whang, "Information distortion in a supply chain: the bullwhip effect," Management Science, vol. 43, no. 4, pp. 546-558, 1997.

[40] H. L. Lee, V. Padmanabhan, and S. Whang, "Information distortion in a supply chain: the bullwhip effect," Management Science, vol. 50, no. 12, pp. 1875-1886, 2004.

[41] H. L. Lee, K. C. So, and C. S. Tang, "The value of information sharing in a two-level supply chain," Management Science, vol. 46, no. 5, pp. 626-643, 2000.

[42] Q. Duan and T. Warren Liao, "Optimization of replenishment policies for decentralized and centralized capacitated supply chains under various demands," International Journal of Production Economics, vol. 142, no. 1, pp. 194-204, 2013.

[43] F. Costantino, G. Di Gravio, A. Shaban, and M. Tronci, "The impact of information sharing and inventory control coordination on supply chain performances," Computers \& Industrial Engineering, vol. 76, pp. 292-306, 2014.

[44] R. Croson and K. Donohue, "Behavioral causes of the bullwhip effect and the observed value of inventory information," Management Science, vol. 52, no. 3, pp. 323-336, 2006.

[45] R. H. Teunter, M. Z. Babai, J. A. C. Bokhorst, and A. A. Syntetos, "Revisiting the value of information sharing in two-stage supply chains," European Journal of Operational Research, vol. 270, no. 3, pp. 1044-1052, 2018.

[46] H. Khosroshahi, S. M. M. Husseini, and M. R. Marjani, "The bullwhip effect in a 3-stage supply chain considering multiple retailers using a moving average method for demand forecasting," Applied Mathematical Modelling, vol. 40, no. 21-22, pp. 8934-8951, 2016.

[47] R. Croson and K. Donohue, "Impact of POS data sharing on supply chain management: an experimental study," Production and Operations Management, vol. 12, no. 1, pp. 1-11, 2003.

[48] A. K. Singh and A. Garg, "Impact of information integration on decision-making in a supply chain network," Production Planning \& Control, vol. 26, no. 12, pp. 994-1010, 2015. 
[49] C. G. Kochan, D. R. Nowicki, B. Sauser, and W. S. Randall, "Impact of cloud-based information sharing on hospital supply chain performance: a system dynamics framework," International Journal of Production Economics, vol. 195, pp. 168-185, 2018.

[50] Q. Li and S. M. Disney, "Revisiting rescheduling: MRP nervousness and the bullwhip effect," International Journal of Production Research, vol. 55, no. 7, pp. 1992-2012, 2017.

[51] A. Keshari, N. Mishra, N. Shukla, S. McGuire, and S. Khorana, "Multiple order-up-to policy for mitigating bullwhip effect in supply chain network," Annals of Operations Research, vol. 269, no. 1-2, pp. 361-386, 2018.

[52] S. M. Disney and D. R. Towill, "Vendor-managed inventory and bullwhip reduction in a two-level supply chain," International Journal of Operations \& Production Management, vol. 23, no. 6, pp. 625-651, 2003.

[53] S. M. Disney, I. Farasyn, M. Lambrecht, D. R. Towill, and W. Van de Velde, "Taming the bullwhip effect whilst watching customer service in a single supply chain echelon," European Journal of Operational Research, vol. 173, no. 1, pp. 151-172, 2006.

[54] X. Zhang and G. J. Burke, "Analysis of compound bullwhip effect causes," European Journal of Operational Research, vol. 210, no. 3, pp. 514-526, 2011.

[55] Y. Wei, H. Wang, and C. Qi, "On the stability and bullwhip effect of a production and inventory control system," International Journal of Production Research, vol. 51, no. 1, pp. 154-171, 2013.

[56] Y. Zhao, Y. Cao, H. Li et al., "Bullwhip effect mitigation of green supply chain optimization in electronics industry," Journal of Cleaner Production, vol. 180, pp. 888-912, 2018.

[57] E. Pastore, A. Alfieri, and G. Zotteri, "An empirical investigation on the antecedents of the bullwhip effect: evidence from the spare parts industry," International Journal of Production Economics, vol. 209, pp. 121-133, 2019.

[58] S. M. Disney and D. R. Towill, "The effect of vendor managed inventory (VMI) dynamics on the bullwhip effect in supply chains," International Journal of Production Economics, vol. 85, no. 2, pp. 199-215, 2003.

[59] F. Costantino, G. Di Gravio, A. Shaban, and M. Tronci, "Smoothing inventory decision rules in seasonal supply chains," Expert Systems with Applications, vol. 44, pp. 304319, 2016.

[60] E. C. Özelkan, C. Lim, and Z. H. Adnan, "Conditions of reverse bullwhip effect in pricing under joint decision of replenishment and pricing," International Journal of Production Economics, vol. 200, pp. 207-223, 2018.

[61] J. Cai, M. Zhong, J. Shang, and W. Huang, "Coordinating VMI supply chain under yield uncertainty: option contract, subsidy contract, and replenishment tactic," International Journal of Production Economics, vol. 185, pp. 196-210, 2017.

[62] J.-c. Li, Y.-w. Zhou, and W. Huang, "Production and procurement strategies for seasonal product supply chain under yield uncertainty with commitment-option contracts," International Journal of Production Economics, vol. 183, pp. 208-222, 2017.

[63] M. G. Güler and M. E. Keskin, "On coordination under random yield and random demand," Expert Systems with Applications, vol. 40, no. 9, pp. 3688-3695, 2013.

[64] T. Hosoda, S. M. Disney, and S. Gavirneni, "The impact of information sharing, random yield, correlation, and lead times in closed loop supply chains," European Journal of Operational Research, vol. 246, no. 3, pp. 292-306, 2015.

[65] S. K. Mukhopadhyay and H. Ma, "Joint procurement and production decisions in remanufacturing under quality and demand uncertainty," International Journal of Production Economics, vol. 120, no. 1, pp. 5-17, 2008.

[66] B. Hu, Y. Feng, and X. Chen, "Optimization and coordination of supply chains under the retailer's profit margin constraint," Computers \& Industrial Engineering, vol. 126, pp. 326-336, 2018.

[67] K. Govindan and M. N. Popiuc, "Reverse supply chain coordination by revenue sharing contract: a case for the personal computers industry," European Journal of Operational Research, vol. 233, no. 2, pp. 326-336, 2014.

[68] O. D. Palsule-Desai, "Supply chain coordination using revenue-dependent revenue sharing contracts," Omega, vol. 41, no. 4, pp. 780-796, 2013.

[69] Y. Li, B. Wang, and D. Yang, "Research on supply chain coordination based on block chain technology and customer random demand," Discrete Dynamics in Nature and Society, vol. 2019, Article ID 4769870, 10 pages, 2019.

[70] B. Li, P.-W. Hou, P. Chen, and Q.-H. Li, "Pricing strategy and coordination in a dual channel supply chain with a risk-averse retailer," International Journal of Production Economics, vol. 178, pp. 154-168, 2016.

[71] J. Zhang, G. Liu, Q. Zhang, and Z. Bai, “Coordinating a supply chain for deteriorating items with a revenue sharing and cooperative investment contract," Omega, vol. 56, pp. 37-49, 2015.

[72] J. Chen, H. Zhang, and Y. Sun, "Implementing coordination contracts in a manufacturer Stackelberg dual-channel supply chain," Omega, vol. 40, no. 5, pp. 571-583, 2012.

[73] A. Y. Ha, "Supplier-buyer contracting: asymmetric cost information and cutoff level policy for buyer participation," Naval Research Logistics, vol. 48, no. 1, pp. 41-64, 2001.

[74] Y. Pezeshki, A. Baboli, N. Cheikhrouhou, M. Modarres, and M. R. Akbari Jokar, "A rewarding-punishing coordination mechanism based on Trust in a divergent supply chain," European Journal of Operational Research, vol. 230, no. 3, pp. 527-538, 2013.

[75] J. Xu, Q. Qi, and Q. Bai, “Coordinating a dual-channel supply chain with price discount contracts under carbon emission capacity regulation," Applied Mathematical Modelling, vol. 56, pp. 449-468, 2018.

[76] B. Zheng, C. Yang, J. Yang, and M. Zhang, "Dual-channel closed loop supply chains: forward channel competition, power structures and coordination," International Journal of Production Research, vol. 55, no. 12, pp. 3510-3527, 2017.

[77] J. J. Nativi and S. Lee, "Impact of RFID information-sharing strategies on a decentralized supply chain with reverse logistics operations," International Journal of Production Economics, vol. 136, no. 2, pp. 366-377, 2012.

[78] J. Luo and X. Chen, "Coordination of random yield supply chains with improved revenue sharing contracts," European J. of Industrial Engineering, vol. 10, no. 1, pp. 81-102, 2016.

[79] A. Yenipazarli, "To collaborate or not to collaborate: prompting upstream eco-efficient innovation in a supply chain," European Journal of Operational Research, vol. 260, no. 2, pp. 571-587, 2017.

[80] Z. Song, S. He, and G. Xu, "Decision and coordination of fresh produce three-layer E-commerce supply chain: a new framework," IEEE Access, vol. 7, pp. 30465-30486, 2019.

[81] R. D. Banker, I. Khosla, and K. K. Sinha, "Quality and competition," Management Science, vol. 44, no. 9, pp. 1179-1192, 1998.

[82] A. Hassanzadeh, A. Jafarian, and M. Amiri, "Modeling and analysis of the causes of bullwhip effect in centralized and decentralized supply chain using response surface method," 
Applied Mathematical Modelling, vol. 38, no. 9-10, pp. 2353-2365, 2014.

[83] D. Fu, C. M. Ionescu, E.-H. Aghezzaf, and R. De Keyser, "Decentralized and centralized model predictive control to reduce the bullwhip effect in supply chain management," Computers \& Industrial Engineering, vol. 73, pp. 21-31, 2014.

[84] D. W. Cho and Y. H. Lee, "The value of information sharing in a supply chain with a seasonal demand process," Computers \& Industrial Engineering, vol. 65, no. 1, pp. 97-108, 2013.

[85] Z. Li, S. M. Gilbert, and G. Lai, "Supplier encroachment under asymmetric information," Management Science, vol. 60, no. 2, pp. 449-462, 2014.

[86] T. Li and H. Zhang, "Information sharing in a supply chain with a make-to-stock manufacturer," Omega, vol. 50, pp. 115-125, 2015. 